Revista lus et Praxis, Año 24, No 2, 2018, pp. 223 - 262

ISSN 0717 - 2877

Universidad de Talca - Facultad de Ciencias Jurídicas y Sociales

Prueba pericial y su impacto en los errores del sistema de justicia penal

Mauricio Duce J.

Trabajo recibido el 10 de enero y aprobado el 20 de julio de 2017

\title{
Prueba pericial y su impacto en los errores del sistema de justicia penal: antecedentes comparados y locales para iniciar el debate*
}

\author{
Mauricio Duce J.**
}

\section{RESUMEN}

El trabajo contiene los resultados de la primera parte de una investigación destinada a explorar el uso que en nuestro país se realiza de la prueba pericial en los procesos penales de manera de identificar si están presentes o no ciertos riesgos descritos en la experiencia comparada asociados a la posibilidad de producir decisiones erradas. En concreto, se explica brevemente cómo la prueba pericial ha ido adquiriendo un rol cada vez más relevante en el funcionamiento de los sistemas de justicia criminal contemporáneos. Luego se revisa la evidencia comparada que muestra que el uso inadecuado de esta prueba es un factor que aumenta la probabilidad de los sistemas de justicia criminal a cometer errores y particularmente se identifican y explican las principales razones que producen este fenómeno. Finalmente, se presenta la evidencia disponible en Chile sobre la materia en distintas fuentes que permite apreciar, al menos en forma preliminar, que se está en presencia de un área de riesgo que requiere ser estudiada con más cuidado.

\section{ABSTRACT}

This paper contains the main findings of the first part of a research conducted to explore, if in the common use of expert evidence in our country, can be identified the risks described in the comparative literature as factors associated to the production of wrongful decisions. In this regard, it describes succinctly how the expert evidence has been acquiring a growing importance in its role on modern criminal justice systems. Then, it reviews how comparative research on this subject shows that the inadequate use of this type of evidence may increase the chances of making mistakes by the criminal justice system, and then main explanations to this phenomenon are identified and explained. Finally, the available evidence on this regard in our country is reviewed from several sources by which is possible to show, at list in a preliminary way, that we are in a dangerous area where more empirically oriented research is required.

PaLABRAs Clave

Prueba pericial, peritos, condenas erróneas, justicia penal, justicia penal comparada

\footnotetext{
* Este trabajo ha sido elaborado en el marco del proyecto Fondecyt Regular № 1150073 "Errores de la justicia penal: investigación empírica y dogmática sobre sus causas en nuestro país y recomendaciones para evitarlos". El autor agradece el valioso apoyo realizado por los ayudantes del proyecto en sus distintas etapas: Eduardo Alcaíno y Ricardo Lillo.

** Profesor titular Facultad de Derecho Universidad Diego Portales (Santiago, Chile). Magíster en Ciencias Jurídicas (J.S.M.) Universidad de Stanford, Estados Unidos. Correo electrónico: mauricio.duce@udp.cl.
} 
KEY WORDS

Expert evidence, expert witnesses, wrongful convictions, criminal justice, comparative criminal justice

\section{Introducción}

La evidencia comparada da cuenta de dos fenómenos que se vienen produciendo en forma paralela en relación a la prueba pericial en los sistemas de justicia penal ${ }^{1}$. El primero de ellos es que su uso parece ser cada vez más frecuente, es decir, se trata de un medio probatorio que habitualmente es presentado y considerado para decidir casos penales ${ }^{2}$. A esto se suma un segundo hallazgo que muestra que -debido a diversos problemas en su presentación y valoración- este medio constituye uno de los factores más relevantes entre aquellos que aumentarían las probabilidades de error en los sistemas de justicia penal, especialmente el de condenar a inocentes ${ }^{3}$.

Como el lector observará, se trata de fenómenos con consecuencias extremadamente delicadas para cualquier sistema legal, y en especial respecto de ciertos valores comunes que hoy en día éstos pretenden proteger, lo que ha llevado a examinar críticamente la regulación legal del $\mathrm{mismo}^{4}$. En este contexto, el presente trabajo contiene los resultados de la primera parte de una investigación destinada a explorar e identificar si es que en nuestro país están presentes o no ciertos riesgos descritos en la experiencia comparada, especialmente aquellos asociados a la posibilidad de producir decisiones erradas como consecuencia del uso inadecuado de la prueba pericial. De esta forma, el objetivo central de este artículo será entregar un panorama comparado de los fenómenos descritos y analizar la evidencia actualmente disponible en Chile que nos permita identificar, de manera preliminar, si estamos en presencia o no de una cuestión problemática

\footnotetext{
1 Aun cuando me parece se trata de un tema relativamente pacífico en la literatura procesal penal, esclarezco que para los efectos de este trabajo entenderé por prueba pericial aquella que consiste en la presentación de una opinión o conclusión emanada de un experto o perito que ha sido requerida de manera explícita por el sistema de justicia penal y que recae sobre una materia que se encuentra fuera del conocimiento común u ordinario de los jueces. Por perito, a su vez, entiendo a la persona que -producto de su conocimiento especial o experiencia- está en condiciones de aportar conclusiones o entregar opiniones sobre temas que están fuera de la esfera de conocimiento de los jueces y que el sistema de justicia requiere para resolver los casos que conoce. En la doctrina comparada puede verse, entre otros: ROXIN (2003), pp. 238-240 y MAIER (2011), pp. 147-150. En Chile, entre otros: DUCE (2013 a), pp. 29-36.

${ }^{2}$ Véase infra capítulo 1.

${ }^{3}$ Véase infra capítulo 2.

${ }^{4}$ Esto ha tenido enorme impacto en cuestiones vinculadas al desarrollo de reglas especiales para controlar la admisibilidad de la prueba pericial. Una visión comparada sobre este punto puede verse en: Jackson y Summers (2012), pp. 74-76; Freckelton et al. (2016), pp. 19-32. En el caso chileno puede verse: DUCE (2010), pp. 45-86.
} 
en nuestro país. A partir de este trabajo, una segunda parte de la investigación - que dará lugar a otro texto- presentará los resultados de un estudio empírico destinado a identificar las prácticas y usos de la prueba pericial en el proceso penal nacional que pueden resultar más problemáticas o riesgosas.

Para el logro del objetivo propuesto, el trabajo se divide en tres capítulos además de la introducción y de una breve sección final destinada a las conclusiones. En el capítulo primero explicaré cómo la prueba pericial ha ido adquiriendo un rol cada vez más relevante en el funcionamiento de los sistemas de justicia criminal contemporáneos. En el segundo, revisaré la evidencia comparada que muestra que el uso inadecuado de la prueba pericial es un factor que aumenta la probabilidad de los sistemas de justicia criminal a cometer errores y me detendré particularmente en identificar las principales razones que explican este fenómeno. Finalmente, un tercer capítulo estará destinado a presentar la evidencia disponible en Chile sobre la materia en distintas fuentes, para determinar de manera preliminar si estamos frente a un área en donde potencialmente existen riesgos relevantes que debieran llevar a preocuparnos más y profundizar la investigación en la materia.

Debo reiterar que esta es la primera parte de una investigación más amplia y, por decirlo de alguna forma, representa el marco teórico y la revisión de la evidencia nacional actualmente disponible. Por lo mismo, sólo me valdré de información ya publicada sin todavía mostrar hallazgos de mi propia investigación de tipo empírico.

\section{El uso de la prueba pericial en los procesos penales contemporáneos}

Una revisión panorámica de la literatura especializada en materia de prueba pericial permite identificar que existe un importante consenso a nivel comparado acerca de que su uso en los sistemas judiciales es cada vez más frecuente y masivo. Me parece que esta idea queda muy bien reflejada por Jeuland, quien la ha enmarcado en un contexto de evolución histórica y social de los sistemas judiciales al señalar: "Cada época tiene una predilección por un medio de prueba. Los cristianos de la Edad Media tenían una preferencia por las ordalías y los juramentos. El Ancien Régime desarrolló a la prueba documental y la confesión por medio de la tortura. Nuestra época tiene una predilección por la evidencia de expertos. Ciertamente la confesión, el testimonio, los documentos o el juramento continúan siendo utilizados, pero el medio de prueba que atrae la atención, responde a nuestras expectativas y levanta discusión es la evidencia experta" ${ }^{5}$.

${ }^{5}$ Citado por Dwyer (2008), p. 1 (traducción del autor). 
En esta línea, autores que pertenecen a distintas tradiciones jurídicas, y que escriben desde perspectivas diversas de análisis, destacan que los sistemas judiciales recurren cada vez con más frecuencia al uso de esta prueba para decidir los casos que conocen. Así, por ejemplo, tanto la doctrina que se preocupa del tema en la tradición anglosajona ${ }^{6}$ como en la de cuño europeo continental ${ }^{7}$ concluyen básicamente el mismo punto, no existiendo diferencias relevantes si es que se escribe desde la óptica del proceso penal ${ }^{8} \mathrm{o}$ los procesos civiles ${ }^{9} \mathrm{o}$ desde perspectivas con énfasis diferente, por ejemplo, que ponen acento en los problemas legales ${ }^{10}$, epistemológicos ${ }^{11}$ o científicos que genera el uso de esta prueba ${ }^{12}$.

"En el contexto de esta tradición la cantidad de autores que se refieren al tema es impresionante. Sólo me
detengo en ejemplos de cuatro países. En los Estados Unidos Mauet ha afirmado que "Vemos cada vez
más peritos en toda clase de proceso. Es un acontecimiento diario. Casi todos los procesos actualmente
tienen peritos" MAUEt (2007), p. 20. En Canadá, Gold, afirma que "Conocimiento y expertizaje han
crecido exponencialmente en nuestras sociedades y el incremento del consumo de los tribunales de
prueba pericial refleja esa realidad en nuestro mundo moderno". Gold (2003), p. 4 (traducción del
autor). En el contexto de Gran Bretaña, Dennis enfatiza que "... hay una gran cantidad de materias en
las que la prueba pericial puede ser rendida y la lista está creciendo". DeNNIS (2010), p. 887 (traducción
del autor). En Australia, Freckelton describe este mismo fenómeno poniendo énfasis en el aumento
de oferta señalando: "Las páginas de 'evidencia experta' (en los servicios de suscripción) muestran la
extensión con la que las ciencias forenses han proliferado y evolucionado, y se han profesionalizado
y especializado". FreCKELTON (2009), p. 1.120 (traducción del autor).
7 En Italia, Federico Stella describe a este fenómeno señalando "...la ola de procedimientos judiciales
que relacionan a la ciencia y la tecnología en los últimos decenios ha provocado un espectacular
aumento del número y tipo de expertos, Ilamados a participar en los procesos..." STELLA (2003), p. 32.

${ }^{8}$ Por ejemplo, sobre este punto Roxin, tal vez si uno de los principales referentes en el área penal en la tradición continental, señala sobre esta materia "En el procedimiento penal moderno, en el que la aclaración científica de cuestiones que no son jurídicas juega un papel cada vez más importante, el perito ha alcanzado, con frecuencia, una posición dominante en la práctica..." Roxin (2003), p. 240.

${ }^{9}$ Taruffo ha señalado, específicamente refiriéndose a los procesos civiles, que "...cada vez con más frecuencia las materias de litigio civil involucran hechos que van más allá de las fronteras de una cultura común o promedio, que es el tipo de cultura no jurídica de un juez o un jurado" TARUFFo (2008), p. 90. Agrega, refiriéndose a la prueba científica, que "...en realidad, la frecuencia con que se recurre a la ciencia para suministrar prueba de los hechos de un caso está creciendo en todos los sistemas procesales" TARUFFO (2008), p. 97. En la tradición anglosajona Beecher-Monas señala que "La evidencia científica es una faceta inescapable de la litigación moderna. Es fundamental para la justicia criminal y para la litigación civil". (Traducción del autor). BeEcher-Monas (2007), p. 4.

${ }^{10}$ Buena parte de los autores que he citado previamente ponen éste énfasis en su análisis de la prueba pericial por lo que no repito nuevamente las citas.

11 Desde esta perspectiva escribe Marina Gascón, quien señala en este punto: “En estos últimos años los constantes avances científicos y técnicos han tenido un profundo impacto en el ámbito de la prueba y juegan un papel cada vez más importante en todos los procesos". GASCÓn, Marina (2013), p.181.

${ }^{12}$ En esta dirección el texto más relevante está constituido por el informe preparado por la Academia Nacional de Ciencias de los Estados Unidos en el año 2009. National Research Council (2009). También sugiero revisar: Peterson et al. (2010). En un área específica como lo es la psicología forense, Cutler y 
Se trata también de una opinión que ha sido sostenida en nuestro país por la escasa doctrina disponible en la materia ${ }^{13}$ y por diversos autores a nivel regional, incluso desde hace bastante tiempo ${ }^{14}$.

La pregunta obvia que surge a partir de este consenso tan transversal es acerca de las razones que explicarían este fenómeno. Estimo que ello es consecuencia de un conjunto de factores vinculados al desarrollo social, tecnológico y económico experimentado en las últimas décadas en las sociedades occidentales contemporáneas, tal como es recogido en varias de las opiniones citadas ${ }^{15}$. Es decir, no se trata de un fenómeno "causado" por los sistemas jurídicos. Es por eso que no es tan importante como elemento explicativo el tipo de proceso desde el cual se escriba, la tradición jurídica a la que se pertenezca o el punto de vista de análisis preferente. Debido a procesos sociales que van más allá del sistema legal específico, al parecer todos los países estamos experimentado una situación muy similar. Obviamente esto no quiere decir que este fenómeno de la realidad no produzca un impacto relevante al funcionamiento de los sistemas jurídicos y que, por lo mismo, ellos deban hacerse cargo. Como señala Vázquez, producto del rol que estaría cumpliendo la opinión experta en nuestras sociedades, “...

\footnotetext{
Zapf señalan respecto a la realidad de los Estados Unidos que "El conocimiento psicológico es usado en la actualidad en forma regular en juicios, apelaciones y casos ante las cortes supremas a nivel estatal y federal y es usada para la elaboración de leyes en tópicos relevantes. Psicólogos rutinariamente entregan testimonio sobre acusados, litigantes y aspectos psicológicos en tribunales de juicio oral". CUtLer y ZAPF (2014), p. xix. (Traducción del autor).

${ }^{13}$ En esta dirección CASTILLo (2013), pp. 288-289 y DuCE (2013 a), pp. 45-46.

${ }_{14}$ Por ejemplo, en la primera mitad del siglo XX Salort, citando a la doctrina procesal de la época, sostenía que "hoy más que nunca, con el progreso de las ciencias y de las artes, este medio de prueba se hace indispensable para el juez..." SALORT (1949), p. 139. Más cercano en el tiempo, Devis Echandía indicaba que "La importancia de esta prueba es cada día mayor en los procesos penales, civiles o de otra jurisdicción". DevIs (1984), p. 125. A modo ejemplar cito a un autor más moderno y estrechamente vinculado al proceso de reformas a la justicia penal en la región. Así, Binder señala que la prueba pericial adquiere "...una importancia cada vez mayor porque la ciencia convertida en tecnología es de uso cada vez más frecuente en los procesos criminales". BINDER (2013), p. 13.

15 Para no volver sobre ellas, agrego las palabras del integrante de la Corte Suprema de los Estados Unidos Stephen Breyer quien, en la introducción de un texto de referencia sobre evidencia científica escrito por científicos para los jueces, señala "En esta época de ciencia, la ciencia debiera esperar encontrar una calurosa bienvenida, tal vez un hogar permanente, en nuestras cortes. La razón es simple. Las disputas legales presentadas ante nosotros involucran crecientemente los principios y herramientas de la ciencia". BREYER (2011), p. 2. Esto incluso podría extenderse más allá de la cultura occidental. He Jiahong escribe respecto a la situación en China señalando: "Desde el siglo XIX el uso de evidencia científica en el área de la justicia penal se ha desarrollado rápidamente y ahora ocupa un rol central". JIAHON (2016), p. 31 (Traducción del autor).
} 
en el derecho se afrontan algunos nuevos problemas mientras otros antiguos se replantean"16.

No puedo desarrollar en este texto una explicación detallada acerca de la multiplicidad de procesos sociales que generan esta coincidencia, ya que ello me Ilevaría a temas bastante alejados a los que un trabajo como este puede abordar razonablemente. Sólo me interesa afirmar que se trata de una situación que está presente en nuestra realidad cotidiana y que todo indica se seguirá incrementando a futuro. Es decir, pienso que la evolución natural de nuestras sociedades y sistemas judiciales hará que la prueba pericial tendrá aún mayor presencia que la ya tiene en la actualidad en nuestros procesos legales. Por ejemplo, piénsese en el fenómeno de masificación y ampliación de cobertura que ha experimentado la educación superior en nuestro país, lo que explica la mucho mayor disponibilidad de expertos capaces de comparecer en juicio para prestar opiniones periciales que lo que había hasta hace poco en Chile ${ }^{17}$. Por otra parte, la cada vez mayor especialización y tecnificación, también presente en el propio sistema judicial (piénsese en los tribunales ambientales, eléctricos, aduaneros, etc.), genera también la necesidad creciente de contar con expertos que permitan explicar materias que salen de la esfera del conocimiento común. En fin, así sería posible identificar muchos otros factores sociales específicos que pudieran explicar el punto que he venido sosteniendo ${ }^{18}$. Por ahora me interesa detenerme aquí para examinar alguno de los impactos que este fenómeno está teniendo en el funcionamiento del sistema de justicia penal.

\section{El impacto de la prueba pericial en los errores del sistema de justicia penal: información comparada}

Como señalé en la introducción, el propósito de este capítulo es revisar la evidencia disponible acerca del impacto que tendría el uso de la prueba pericial en el funcionamiento de los sistemas de justicia penal, en particular al aumentar la probabilidad de decisiones erróneas. Para estos efectos dividiré el capítulo

\footnotetext{
16 VÁsquez (2015), p. 25.

17 De acuerdo a información entregada por la OCDE nuestro país habría sido el que aumentó en mayor porcentaje la cobertura en educación superior en América Latina en el período comprendido entre los años 2000 a 2010, pasando de un 14,3\% a un 33,6\% del total de jóvenes entre 18 y 24 años. Véase: Muñoz y SalazAr (2014). Todo indica que las reformas a la educación superior que se vienen promoviendo en estos últimos años debieran aumentar aún más esta cobertura.

18 Por ejemplo, Mauet señala que la explosión del litigio civil de responsabilidad extracontractual del siglo XX en los Estados Unidos es en parte consecuencia de los accidentes producidos por el desarrollo y masificación de autos, camiones y carreteras. Este fenómeno tuvo como consecuencia también la explosión en el uso de prueba pericial, todo lo cual le permite concluir que "El mundo de los peritos es, en realidad un fenómeno del siglo veinte". Véase: MaUet (2007), p. 21.
} 
en tres secciones. En la primera, entregaré información disponible en un par de países que de manera paradigmática muestran que el uso de la prueba pericial es un factor relevante en la producción de errores del sistema. En la segunda, me detendré en la explicación más detallada de los problemas específicos que explican este impacto. En la tercera, abordaré las dificultades que presenta la valoración de la prueba pericial presentada en juicio en los sistemas de justicia penal, y que complementa la explicación de la sección previa.

\subsection{La magnitud del problema: evidencia en algunos países paradigmáticos}

Los estudios comparados sobre condena de inocentes suelen enfatizar que el uso inadecuado de prueba pericial constituye uno de los principales factores que explican los errores del sistema. Cubrir con rigurosidad a todos los países en donde existe información en la materia es una tarea imposible a la luz de los propósitos de este trabajo. Por eso me detengo en la presentación de información de dos casos paradigmáticos en los que esta cuestión ha sido debatida con mayor profundidad. Uno de ellos debido a la existencia de información empírica muy significativa y, el otro, por el debate generado en diversas instancias oficiales acerca del problema.

El país donde más se investigado este tema desde una perspectiva empírica es Estados Unidos. Así, los datos provenientes del Innocence Project ${ }^{19}$ muestran, de manera consistente en el tiempo, que el uso impropio de prueba pericial constituye el segundo factor de mayor relevancia en los casos de condenas erróneas que ellos han representado. Se trataría de un aspecto presente en alrededor del 50\% de los casos con exoneración de personas condenadas en las que se acreditó con posterioridad su inocencia, tan solo por debajo de los reconocimientos oculares errados que sería el aspecto de mayor incidencia ${ }^{20}$.

Una segunda base de datos que muestra la magnitud del problema en los Estados Unidos es la del National Registry of Exonerations (Registro Nacional de Exoneraciones o NRE). En particular, corresponde a un proyecto conjunto llevado adelante por las facultades de derecho de las universidades de Michigan y Northwestern destinado a identificar y registrar casos de personas inocentes condenadas y luego exoneradas a partir del año 1989, por todo tipo de métodos

19 Se trata de una institución creada en los Estados Unidos el año 1992 por Barry Scheck y Peter Naufeld dedicada a exonerar a personas condenadas erróneamente a través de la demostración de su inocencia utilizando principalmente evidencia de ADN. Mayores antecedentes pueden verse en: www. innocenceproject.org [visitado el 21 de diciembre de 2016].

20 Los datos disponibles al mes de agosto de 2016 muestran que en 300 casos de exoneraciones en los que se ha hecho el análisis (a la misma fecha el sitio del proyecto registra 343 casos de exonerados), en un $51 \%$ se presenta un problema con el uso de la prueba pericial. Disponible en: http://www. innocenceproject.org/causes/unvalidated-or-improper-forensic-science/ [visitado el 21 de diciembre de 2016]. 
(no exclusivamente ADN) ${ }^{21}$. Se trata de una base de datos más amplia y, por lo mismo, sus resultados tienen algunas diferencias con los del Innocence Project. Este último, al poner foco sólo en casos de exoneración por uso ADN, genera un perfil diferente de los mismos en donde la presencia de prueba pericial sería más común en otro tipo de casos que conoce el sistema ${ }^{22}$. No obstante estas diferencias, la base de datos del NRE coincide en que estamos en presencia de uno de los principales factores que contribuyen a la producción de condenas erróneas. Se trataría del cuarto en orden de frecuencia estadística, estando presente en un $23 \%$ de los $\operatorname{casos}^{23}$.

La literatura en los Estados Unidos destaca el aporte que ha significado la investigación de los factores que producen condenas erróneas a partir de casos de personas inocentes exoneradas. No obstante lo anterior, en los últimos años se ha venido generando un debate metodológico respecto de las limitaciones que tendría dicha aproximación para reflejar fielmente la realidad. En particular, se plantea como potencial problema el sesgo que introduciría establecer un vínculo de causalidad a partir de muestras basadas en casos de exoneración ${ }^{24}$. Por lo mismo, se ha venido desarrollando una interesante investigación empírica en la que se ha trabajado en forma paralela con casos de condenas erróneas y casos denominados "near misses" (que podrían ser traducidos como casos cerca de errores o en los

${ }^{21}$ Mayor información en: http://www.law.umich.edu/special/exoneration/Pages/about.aspx [visitado el 21 de diciembre de 2016].

22 Por ejemplo, los delitos de violación son bastante más frecuentes en la base de datos del Innocent Project que la del NRE ya que en ellos suele haber evidencia forense que se obtiene de la propia víctima. Sobre este punto, véase: GARRET (2011), pp. 89, 313. En esta dirección, un estudio empírico destinado a verificar las evidencias materiales colectadas rutinariamente en la investigación de casos en los Estados Unidos muestra que ello ocurre de manera extensiva en delitos de homicidios, un poco menos en las violaciones y muy limitadamente en delitos como los asaltos, los robos y los hurtos. Véase: Peterson et al. (2010), p. 8. De otra parte, el mismo Innocent Project estima que entre el 90 a $95 \%$ de los casos que conoce el sistema de justicia criminal no pueden ser objeto de una exoneración por ADN debido a que no es posible encontrar evidencia biológica que permita efectuar el test respectivo. Véase en: http://www.innocenceproject.org/causes/unvalidated-or-improper-forensic-science/ [visitado el 21 de diciembre de 2016].

${ }^{23}$ La última información disponible en la página al mes de agosto de 2016 muestra que se trataría de un factor presente en 431 de los 1858 casos registrados a esa fecha. Analizado por tipo de delitos, este factor aumentaría a un $31 \%$ tratándose de ataques sexuales, lo que permite comprender las diferencias con los resultados del Innocence Project que expliqué en el texto principal. Información detallada incluyendo otras categorías de delitos puede verse en:

http://www.law.umich.edu/special/exoneration/Pages/ExonerationsContribFactorsByCrime.aspx [visitado el 21 de diciembre de 2016].

${ }^{24}$ Una explicación panorámica acerca de los métodos de investigación y sus límites, haciendo un llamado a introducir nuevas aproximaciones puede verse en: Gould et al. (2014 a), pp.73-89. 
que casi se produce un error $)^{25}$. La particularidad de estos últimos es que el sistema fue capaz de discriminar, antes de la condena, la inocencia del imputado. La idea de estas investigaciones es verificar qué ocurre en casos donde los sistemas de justicia criminal tuvieron la posibilidad de darse cuenta de los errores antes de una condena y compararlos con aquellos en que eso no ocurrió. Los resultados de esta nueva línea de investigación ratifican que el uso de prueba pericial es un factor importante que aumenta la probabilidad de error del sistema. Más aún, han proporcionado información nueva e interesante acerca de los aspectos más problemáticos en su uso, como veré un poco más adelante ${ }^{26}$.

En definitiva, distintas bases de datos e investigaciones realizadas en los Estados Unidos identifican el uso de prueba pericial como un factor relevante para la explicación de errores del sistema de justicia penal. En la próxima sección analizaré los problemas específicos identificados, aunque por ahora me basta que el lector comprenda se trata de un tema que cuenta con bastante evidencia empírica de soporte.

Otro ejemplo donde el impacto de la prueba pericial en la producción de condenas erróneas ha sido objeto de preocupación y estudio es el Reino Unido. Esto, aun cuando no se cuenta con iniciativas que hayan sistematizado casos de manera similar a la que se ha realizado en los Estados Unidos que permitan dimensionar la escala probable o magnitud estadística del problema ${ }^{27}$. Sin embargo, se trata de un caso interesante de revisar ya que la consciencia pública del problema ha generado un movimiento de distintos órganos oficiales destinado a implementar políticas de diverso tipo, incluyendo reformas legales y cambios jurisprudenciales, con el propósito de minimizar los riesgos que el uso de esta prueba tendría en materia de errores del sistema.

En este contexto, una serie de casos de condenas de inocentes de alto perfil público producidos en los últimos 20 años generaron enorme debate y una serie de iniciativas destinadas a revisar el tratamiento de la prueba pericial en Reino Unido $^{28}$. El primer desarrollo estuvo en la elaboración de un reporte realizado

\footnotetext{
25 Más coloquialmente se podría hablar de los casos de "casi error".

${ }^{26}$ La investigación principal en esta nueva línea de trabajo es un estudio financiado con fondos del National Institute of Justice de los Estados Unidos cuyos resultados fueron publicados en marzo de 2013. El estudio involucró el análisis de 460 casos (260 de condena de inocentes y 200 de cerca de error) producidos entre los años 1980 y 2012. Los resultados pueden verse en: Gould et al. (2013). Una versión reducida producida como un texto académico en: Gould et al. (2014b), pp. 471-522.

27 Naughton (2013), p. 105.

28 El mismo trabajo de Naughton documenta varios de estos casos de condena de inocentes revertidos por cortes de apelaciones por mal uso de evidencia científica y de peritajes en general que fundaron la condena inicial. NauGHTON (2013), pp. 95-105. Un análisis más detallado de casos, pero focalizado sólo en un par de ellos y en idioma castellano, puede verse en: RoBERTs (2013), pp. 134-180.
} 
por el Comité de Ciencia y Tecnología de la Cámara de los Comunes (House of Commons Science and Technology Committee) en el año 2005. En este, se presentaron un conjunto de propuestas tendientes a mejorar el uso de peritajes para evitar errores del sistema de justicia penal, asumiendo que el mal uso de esta prueba era una causa de condenas erróneas ${ }^{29}$.

Como respuesta a esto -pero también producto de la preocupación generada por los casos de condenas de inocentes de la época por uso errado de prueba pericial- la Law Comission de Inglaterra y Gales ${ }^{30}$ produjo un reporte cuyo foco fue generar debate y obtener retroalimentación para elaborar una propuesta de modificación legal destinada a establecer reglas más estrictas para la admisibilidad de la prueba pericial en los procesos penales. En la justificación de dicha propuesta se pone especial énfasis en la necesidad de elevar estándares de admisibilidad a juicio de este tipo de prueba, frente a una práctica muy extendida de laissez-faire de los tribunales penales ${ }^{31}$. Esta primera propuesta se transforma, luego de haber recibido respuestas de varias instituciones y expertos, en un borrador de proyecto de reforma legal definitivo y presentado al gobierno a través de un nuevo reporte que fue publicado el año $2011^{32}$. En la justificación del borrador se vuelve a insistir en que la nueva legislación no se funda en un problema meramente teórico sino en uno real, acreditado en una serie de casos de condenas erróneas producidos en Inglaterra y Gales que demostraban los riesgos en el uso de esta evidencia ${ }^{33}$. La expectativa sobre la que descansa la propuesta es que estándares más estrictos de admisibilidad podrían impedir que algunas pruebas periciales de baja confiabilidad, como las que había generado condenas erróneas en los casos analizados, ingresaran a juicio y pudieran formar convicción de culpabilidad respecto a los acusados.

\footnotetext{
${ }^{29}$ Entre otras cosas se recomendaban medidas vinculadas a mejorar la capacitación de jueces y abogados y el desarrollo de instancias institucionales que promovieran mejor comunicación entre las comunidades de expertos y los integrantes del sistema de justicia criminal. Véase: House Of Commons SCience And TeChnology Committee (2005).

${ }^{30}$ Se trata de un cuerpo autónomo creado por ley el año 1965 con el propósito de supervisar que la legislación de ambos países sea justa, moderna, simple y costo-efectiva. Mayor información puede verse en su página web http://www.lawcom.gov.uk/ [visitado el 21 de diciembre de 2016].

${ }^{31}$ En dicho reporte se analizan de modo ejemplar varios de estos casos de condenas de inocentes generados por uso inadecuado de prueba pericial. THe LAw Commission (2009), pp. 10-17.

32 The Law Commission (2011), p. 211. La propuesta plantea la necesidad de dictar una legislación específica (Criminal Evidence (experts) Bill) sobre la prueba pericial en materia penal que pudiera recoger tanto los desarrollos jurisprudenciales y normativos ya experimentados en Inglaterra y Gales en un solo cuerpo legal, como perfeccionar estos a través de una propuesta que se hiciera cargo de los problemas centrales en la base del diagnóstico realizado por la Comisión.

${ }^{33}$ The Law Commission (2011), pp. 1-3. Aquí nuevamente se contiene un breve análisis de casos paradigmáticos.
} 
El año 2013 el gobierno rechaza la propuesta de legislar realizada en el reporte de la Law Commission de 2011, aun cuando reconocía los riesgos que presenta el uso inadecuado de prueba pericial poco confiable y que las propuestas contenidas en el informe podrían reducir dicho riesgo ${ }^{34}$. No obstante esto, su respuesta recomienda revisar las Reglas de Procedimiento Criminal (Criminal Procedure Rules) con el objeto de entregar mayor información en las etapas tempranas del proceso sobre los peritajes que se intentan utilizar como prueba de manera de mejorar la capacidad de cuestionamiento de litigantes y jueces y así reducir los riesgos de error judicial. Dicha reforma fue finalmente introducida el 14 de octubre de 2014 mediante un cambio a la regla 33.4 (h) que señala que el informe del perito debe incluir información necesaria para permitir al tribunal decidir si "la opinión del experto es suficientemente confiable para admitirla como prueba" ${ }^{\prime \prime 2}$.

En forma paralela a este debate de reforma normativa, las propuestas de la Law Commission han sido incorporadas crecientemente por diversas vías en la práctica judicial al existir niveles importantes de acuerdo en los jueces en Inglaterra y Gales acerca de la magnitud problema de las condenas erróneas generadas por mal uso de la prueba pericial en dicho país ${ }^{36}$.

Como se puede apreciar en este breve recuento de los dos ejemplos de análisis, los problemas que está generando el uso de la prueba pericial en la producción de condenas erróneas son relevantes en el ámbito comparado y crecientemente se ha ido produciendo información empírica que así lo demuestra. Por otra parte, también comienzan a perfilarse algunas respuestas de distintas autoridades de los sistemas de justicia criminal que dan cuenta de la enorme preocupación que está generando este tema. Estimo que no se trata de casos aislados, sino una constante que se está dando en varios países de distintas regiones. Sólo menciono tres ejemplos provenientes de regiones

\footnotetext{
${ }^{34}$ En el documento el gobierno manifiesta sus dudas acerca de los beneficios de introducir las reformas legales propuestas frente a la carencia de datos robustos que indiquen la magnitud real del problema y, especialmente, considerando que las propuestas generarían más costos al funcionamiento del sistema, por ejemplo, por la realización de nuevas y más extensas audiencias. Véase: MINISTRY OF JUSTICE (2013).

${ }^{35}$ Freckelton et al. (2016), pp. 41-42. Esto ha sido complementado a través de cambios en las Criminal Practice Directions 33.A.4, 33.A.5 y 33.A.6 de Inglaterra, las que-si bien no tienen valor de ley-reflejan la preocupación de avanzar en la regulación normativa del uso de la prueba pericial.

${ }^{36}$ Así lo señala el Lord Chief Justice de Inglaterra y Gales a la prensa en noviembre de 2014. Véase: ROZENBERG (2014). Un breve resumen de la evolución jurisprudencial en años recientes en Inglaterra que muestra cómo efectivamente la confiabilidad ha sido admitida como criterio de admisibilidad puede verse en FreCKelton et al. (2016), pp. 228-230.
} 
y tradiciones jurídicas diversas que apuntan en la misma dirección: Canadá37, Alemania ${ }^{38}$ y China. ${ }^{39}$ Con todo, como dije en la introducción de este capítulo, no puedo en este trabajo realizar un análisis exhaustivo sobre cada uno de ellos, más bien me interesa avanzar en la descripción de las razones que la investigación muestra causarían el fenómeno descrito, cuestión que abordaré en la siguiente sección.

\subsection{Los problemas específicos identificados en el ámbito comparado}

La evidencia comparada ha permitido identificar una serie de problemas en el uso de la prueba pericial que explicarían los riesgos de producir condenas a inocentes. Me detengo muy brevemente en los que considero son los cuatro principales.

\subsubsection{El uso de prueba pericial poco confiable}

El primer problema que se ha detectado es la tendencia de los sistemas de justicia penal en el uso de un conjunto de pruebas periciales de muy baja confiabilidad. Esto se produce generalmente como consecuencia del uso de opiniones expertas fundadas en disciplinas de escaso rigor metodológico o científico. La literatura anglosajona agrupa estos casos bajo la noción de Junk Science o ciencia basura ${ }^{40}$. El punto central que se pretende enfatizar es que en muchas oportunidades se utiliza como evidencia en juicio prueba pericial que es presentada con un aura de rigor científico o metodológico, que real-

\footnotetext{
37 El impacto de la prueba pericial en la producción de condenas erróneas en Canadá ha sido tan alto que desde la propia persecución penal se ha abordado como uno de los problemas más relevantes en dos informes realizados por grupos de trabajo de fiscales que han elaborado sendos reportes (2004 y 2011) con el objetivo de prevenirlas. Véase: FPT Heads of Prosecutions Committee Working Group (2004), pp. 115-132, y FPT Heads of Prosecutions Committee (2011), pp. 133-159.

${ }^{38}$ La preocupación por este tema ha sido recogida en la doctrina hace más de cincuenta años en este país. En esta dirección, Hirschberg analiza varios casos de condenas erróneas producidos en Alemania que ubica bajo el concepto de "valoración no crítica de los dictámenes periciales" señalando que numerosas sentencias erróneas tienen su principal causa en "...esa fe ciega de los tribunales en el perito, sobre todo en el dictaminador oficial, y en la deficiente instrucción de la mayoría de los jueces y defensores..". Véase: HiRSChBeRG (1969), pp. 69 -92 (publicación original en alemán en el año 1960).

39 Jiahon ha llamado recientemente la atención acerca de cómo el incorrecto uso e interpretación de la evidencia científica en dicho país ha sido la causa de condenas erróneas en una serie de casos que analiza en su texto. JiAHON (2016), pp. 31-51.

40 Thomas (2015), p. 1039. Thomas explica como este término se popularizó en los Estados Unidos a través de un trabajo publicado por Peter Huber el año 1991. En este describió a la ciencia basura como "la imagen del espejo de la ciencia real, con mucho de la misma forma, pero nada de la misma sustancia" (traducción del autor).
} 
mente no posee y que lleva a los juzgadores a cometer errores en la decisión final. Garret, quien realiza un análisis a partir de la base de datos del Innocent Project, señala que muchos de los exonerados por ese proyecto precisamente han sido condenados como resultado de métodos forenses poco confiables ${ }^{41}$. De la misma forma, la Law Comissión de Inglaterra y Gales ha elaborado una propuesta de reforma legal, destinada a elevar los estándares de admisibilidad, estructurada sobre la base de considerar que un problema frecuente en estos países y que explica las condenas de inocentes ha sido el uso de evidencia no confiable de parte de la persecución penal ${ }^{42}$. En líneas similares existe evidencia en Canadá ${ }^{43}$ y Australia ${ }^{44}$ sobre la incidencia de este factor.

Sobre esta materia, un aporte central desde la comunidad científica ha venido del trabajo desarrollado por la Academia Nacional de Ciencias (National Academy of Sciences o NAS) de los Estados Unidos. El año 2009 el National Research Council de la institución publicó un informe elaborado con el objetivo de contribuir a la mejora de la calidad de las ciencias forenses en dicho país. En él, se identificaron serias deficiencias en el trabajo forense en áreas de común uso en los tribunales penales. Dentro de ellas, el análisis de marcas de mordeduras, los análisis microscópicos de pelos, las marcas de huellas de zapatos, la comparación de voces y el uso huellas digitales. El informe establece que se trata de disciplinas que no tienen grados de confiabilidad mínimos, debido al escaso soporte de investigación científica sobre el que se fundan y que permita validar las premisas básicas y las técnicas sobre las cuáles se construyen ${ }^{45}$. En pocas palabras, se trata de pruebas generadas con base científicas débiles y discutibles. Como se podrá comprender, no es de extrañar que si prueba pericial de uso habitual no tiene soporte científico real, ello sea un motor de decisiones erradas de condena. El lector imaginará el impacto que un informe de esta naturaleza, producido por una institución con alta validación en el mundo científico, ha tenido en dicho país y a nivel mundial ${ }^{46}$.

41 Garret (2011), p. 90.

42 The Law Commission (2011), p. 1.

${ }^{43}$ ROACH (2010), p. 399.

${ }^{44}$ Freckelton et al. (2016), pp. 31-33.

45 National Research Council (2009), pp. 1-33. Una visión que explica de manera sencilla y breve los problemas desde el punto de vista de la comunidad científica puede verse en SERVICK (2016). Disponible en: http://www.sciencemag.org/news/2016/03/reversing-legacy-junk-science-courtroom [Visitado el 21 de diciembre de 2016].

${ }^{46}$ Por ejemplo, en forma reciente el FBI en los Estados Unidos ha admitido errores cometidos en cientos de casos en los que se aplicó la técnica de análisis de pelos. Así, un reporte del año 2015 de 


\subsubsection{El testimonio inválido de los peritos}

Un segundo problema identificado en la literatura comparada es lo que Garret y Naufeld describen como testimonio pericial inválido ${ }^{47}$. Con ello se refieren a que peritos, incluso pertenecientes a disciplinas que no presentan problemas de confiabilidad importante, tienen la tendencia en juicio a realizar afirmaciones y entregar conclusiones que no cuentan con apoyo empírico en su respectiva disciplina. Es decir, el problema se da en la manera en que los expertos reportan e interpretan los resultados obtenidos en sus operaciones al momento de entregar sus testimonios en las audiencias de juicio ${ }^{48}$. El estudio de ambos autores analiza 137 casos de personas exoneradas por el Innocent Project (de un universo total de 232 exonerados a esa fecha) en donde se produjo prueba pericial en juicio. Con base en esto, determinaron que en un $60 \%$ de ellos (82 casos) los analistas prestaron testimonio inválido. Este testimonio básicamente incluye dos hipótesis de errores: uso inadecuado de datos empíricos sobre la población general, y, conclusiones sobre el valor probatorio de la evidencia respectiva que no contaba con apoyo en la evidencia empírica disponible en la propia disciplina ${ }^{49}$. La magnitud del problema les permite identificar a estos autores que no sólo se trata de un comportamiento común de los peritos en juicio sino una práctica prevalente ${ }^{50}$.

El problema descrito por Garret y Naufeld parece ser un patrón común también en la experiencia comparada, según se puede apreciar en la revisión

la Oficina del Inspector General de la institución determinó comportamientos irregulares en la unidad de análisis de pelos. Véase: BBC (2015). Véase también: HSU (2012).

47 Véase: Garret y Naufeld (2009), pp. 7-8.

${ }^{48}$ Garret y Naufeld (2009), pp. 6-8. Por ejemplo, en el estudio se determina que en un $27 \%$ de los casos en que se presentaron analistas de ADN, una tecnología ampliamente validada en la ciencia, hubo declaraciones inválidas en la audiencia de parte de los expertos que comparecieron (p. 15). Siguiendo con este ejemplo, Peter Gill, conocido como uno de los padres fundadores de la disciplina de la técnica del ADN forense, ha sostenido: "Hay pocas dudas... que la interpretación errónea de los perfiles de ADN pueden causar decisiones erradas de la justicia". Gill (2014), p. x. Citado por: MuRPHY (2015), p. xi. (Traducción del autor).

49 Garret y Naufeld (2009), p. 9.

${ }^{50}$ Garret y Naufeld (2009), p. 14. Cabe señalar que los estudios de "near misses" también identifican a este como el problema más frecuente que lleva a condenas erróneas. Gould et al. (2014 a), p. 78. 
de casos en países tan diversos como Inglaterra ${ }^{51}$, Canadá52, o China ${ }^{53}$. Me parece que es fácil comprender el enorme riesgo que para la corrección de las decisiones de los jueces generan estos comportamientos de los expertos.

\subsubsection{El mal comportamiento de los peritos}

\section{Un tercer problema está vinculado al mal comportamiento de los expertos} que trabajan para los sistemas de justicia penal. Por mal comportamiento me refiero no a deficiencias específicas de un experto en un caso particular, sino más bien a comportamientos explícitamente orientados a causar un error. Esto incluiría conductas como: no dar a conocer al acusado evidencia favorable a su caso; fabricar evidencia forense en su contra; y, presentar la opinión forense

51 Uno de los casos más conocidos en Inglaterra sobre este tema es el de Sally Clark, quien fuera condenada el año 1999 como autora del homicidio de dos hijos lactantes (Christopher de dos meses en el año 1996 y Harry, también de dos meses, en el año 1998). La señora Clark siempre sostuvo su inocencia y su defensa se estructuró sobre la base de afirmar que los niños murieron como consecuencia del Síndrome de Muerte Súbita del Lactante. Una prueba decisiva para su condena fue el estudio realizado por el prestigioso pediatra inglés, el Dr. Meadow (quien había sido coronado como "caballero" por la Reina) quien estableció que la probabilidad que se produjeran dos casos del síndrome en una misma familia era de uno en 73 millones y que, por lo tanto, sólo podía pasar en Gran Bretaña una vez al siglo. El problema es que dicho cálculo había sido obtenido infringiendo principios básicos de la ciencia estadística. Así, en un estudio realizado por un profesor del área aplicando correctamente los principios de la disciplina se puedo establecer que la probabilidad era de uno en 130.000, por lo que era posible que se diera más de un caso al año en Gran Bretaña. Sally Clark fue finalmente exonerada en un segundo proceso de apelación el año 2003. Una descripción del caso puede verse en: PAENZA (2013). Disponible en: https://www.pagina12.com.ar/diario/contratapa/13-214264-2013-02-20.html [Visitado el 21 de diciembre de 2016]. Otro análisis del caso y sus consecuencias posteriores puede verse también en NAUGHTON (2013), pp. 102-105.

52 En este país el ejemplo más llamativo ha sido el de los testimonios presentados por el pediatra patólogo forense Dr. Charles Smith en diversos casos. Los problemas detectados en su trabajo como jefe del área en la Provincia de Ontario generaron una "Public inquire" encabezada por el juez Stephen Goudge el año 2007 (se trata de una comisión investigadora designado por el ejecutivo y usualmente encabezado por jueces para investigar en casos de graves errores de la justicia). El reporte del año 2008 muestra que en esta investigación cinco expertos internacionales identificaron serias falencias en las declaraciones de Smith en 20 de 45 casos revisados, 12 de los cuales resultaron en la condena de los acusados. En su informe la comisión llama la atención, entre otras cuestiones, sobre la necesidad de monitorear con más cuidado las declaraciones de los expertos en juicio y poner más atención crítica al lenguaje utilizado por los expertos al expresar sus hallazgos. Información general puede verse en: ROACH (2009), pp. 72-73. Detalles sobre el trabajo de la comisión, conocida como Goudge Inquire, pueden verse en la página web de la misma en donde se contiene diversos documentos e informes de mucho interés: http://www.attorneygeneral.jus.gov.on.ca/inquiries/goudge/index.html [Visitado el 21 de diciembre de 2016].

53 Buena parte de los casos descritos por Jiahon precisamente se vinculan a errores que suponen afirmaciones de los expertos sin soporte empírico en su disciplina o extendiendo los resultados a hipótesis no aplicables. JIAHON (2016), pp. 31-42. 
de manera de asistir indebidamente al trabajo de las policías o los fiscales ${ }^{54}$. Si bien hay casos de mal comportamiento extremadamente graves documentados en países como Estados Unidos ${ }^{55}$ e Inglaterra ${ }^{56}$, en donde algunos expertos han tenido influencia decisiva en decenas o centenas de casos a lo largo de varios años de trabajo, existe un cierto debate acerca de la real magnitud del problema. Así, el estudio de Garret y Naufeld del año 2009 identifica que cerca de un $10 \%$ de los casos analizados incluyó fallas en descubrimiento de evidencia exculpatoria o derechamente fabricación de evidencia ${ }^{57}$. Esa cifra se elevaría a cerca de un 14\% en los estudios del propio Garret al año $2011^{58}$.

Más allá del número relativamente acotado, Garret estima que no se trataría sólo un problema de algunas "manzanas podridas" sino algo un poco más sistémico y, por lo mismo, más extendido. En este contexto, cita estudios que mostrarían que los analistas forenses podrían verse expuestos de manera ${ }^{54}$ NaUGHTON (2013), p. 65. En el último de estos tres comportamientos inadecuados de los peritos, el
asistir indebidamente a la policía o fiscales, se producen intersecciones con el segundo de los problemas
descritos, es decir, el de prestar testimonio inválido a juicio. Los casos del Dr. Meadow en Inglaterra
o del Dr. Smith en Canadá muestran como el problema de ellos no fue sólo de errores en la forma
en que presentaron resultados de sus pericias en los juicios que participaron, sino también que ellos
compartían una cierta concepción de rol que los llevaba a estar dispuestos a ir más allá de lo que el
buen juicio científico exigía. En esta línea: FrECKELTON et al. (2016), p. 69 .

${ }^{55}$ Los casos más famosos y más extremos conocidos son los de Fred Zain y Joyce Gilchrist. Zain trabajó por 13 años en el laboratorio de la policía de West Virginia en los Estados Unidos, donde llegó incluso a ser supervisor de la unidad de sereología. Durante estos años prestó testimonio clave para la condena de diversos acusados en su Estado y en Texas. Luego de una serie de exoneraciones logradas por vía de ADN de personas respecto de las cuales él había declarado su culpabilidad, la Corte Suprema de West Virginia inició una investigación en su contra. Por medio de esta, se descubrieron más condenas erróneas como resultado de su testimonio y un conjunto enorme de irregularidades en su trabajo que dieron cuenta de un problema no casual, sino sistémico, en su desempeño. Mayor detalle sobre el mismo puede verse en: NAUGHTON (2013), pp. 65-66 y GARREt (2011), pp. 252-255. Por su parte, Gilchrist fue una química que trabajó como analista y luego supervisora a cargo de la unidad de sereología del laboratorio forense de la ciudad de Oklahoma perteneciente a la policía de la misma ciudad entre los años 1980 y 2001 en el que fue despedida. Se le atribuye haber prestado testimonio experto con serios problemas, incluyendo falsificación de evidencia, en 23 casos de inocentes condenados a muerte, 11 de los cuales fueron ejecutados. Mayor información puede verse en: Luscombe, Belinda (2001), "When Evidence Lies", en: Times Magazine. Disponible en:

http://content.time.com/time/magazine/article/0,9171,109625,00.html [Visitado el 21 de diciembre de 2016].

${ }^{56}$ Naughton menciona como ejemplo el caso del Dr. Frank Skuse, forense del Home Office británico quien prestó testimonio en el famoso caso de la condena de inocentes conocido como el de los seis de Birminghan. NAUGHTON (2013), pp. 66-68.

57 Garret y Naufeld (2009), p. 76. Se refieren a 13 casos de un total de 137 examinados.

${ }^{58}$ En este trabajo la cifra se eleva a 22 casos, aunque también aumenta el universo de casos examinados (un total de 250 en el cual 153, es decir, el 61\% hubo uso de prueba pericial). GarRet (2011), p. 108. 
inadvertida a sesgos importantes por su trabajo para la policía o los fiscales ${ }^{59}$, producto de fenómenos psicológicos como los "sesgos cognitivos" ${ }^{\text {"60 }}$. Por otra parte, como destaca Edmond, los sesgos de los expertos no sólo se producen de manera consciente, sino que también en muchas ocasiones producto de exponerlos a información irrelevante o prejudicial que no es requerida para elaborar su opinión. Esto puede generar sesgos cognitivos inconscientes igualmente dañinos que los otros ${ }^{61}$. Para concluir este punto, la evidencia comparada muestra que estamos en presencia de un problema bastante importante y que también permite comprender el por qué los sistemas de justicia criminal condenan erróneamente a personas inocentes en hipótesis de este tipo.

Se podría sumar a este problema una cuestión adicional, propia del entorno de funcionamiento de los sistemas penales de corte más bien adversarial. Se trataría del rol cumplido por las propias partes cuyos incentivos estarían en maximizar sus posibilidades en los procesos más que llegar a la verdad. Así, ello las llevaría a favorecer el uso de expertos más motivados por ser fieles a los intereses de quienes los contratan que a los de la ciencia, arte u oficio que profesan. En esta dirección, Susan Haack, luego de describir las diferencias y mostrar las tensiones entre las culturas profesionales de científicos y abogados al alero de los modelos adversariales señala: "... el sistema legal frecuentemente obtiene menos de la ciencia que lo que ella podría ofrecer: los abogados están motivados por las demandas de su profesión a conseguir expertos dispuestos a ensombrecer o seleccionar evidencia de acuerdo a la necesidad de su caso y esto podría incentivar a científicos marginales o menos que honestos a involucrarse en el lucrativo negocio de la prueba pericial..." ${ }^{\prime 62}$.

\subsubsection{El uso tardío de la prueba pericial}

Finalmente, quisiera agregar un cuarto problema en el uso de prueba pericial cuya descripción proviene de las investigaciones realizadas en los casos

\footnotetext{
${ }^{59}$ GarRet (2011), pp. 92-93. En esta misma línea haciendo un análisis general sobre las influencias y sesgos que desarrollan profesionales forenses que trabajan en laboratorios, véase: SAKS y SPELLMAN (2016), pp. 209-210.

${ }^{60}$ Garret explica que la investigación psicológica muestra que los sesgos cognitivos se producen debido a que nuestras creencias, deseos y esperanzas influyen en las cosas que percibimos, como razonamos y nos comportamos. Esto se traduciría, entre otras cosas, en identificar con fines nobles a nuestro comportamiento. Por ejemplo, cuando la policía cree que atrapa a un culpable está haciendo justicia más allá de la forma con que lo haya hecho. GARRET (2011), pp. 266-267. Un análisis de diversas barreras cognitivas para el trabajo policial pude verse en: HARRIS (2012), pp. 78-98.

${ }^{61}$ EDMOnd (2013), pp. 256-257.

62 HaACK (2003), p. 208.
} 
de los antemencionados "near misses". Se trata del uso y evaluación tardía de la evidencia experta en las investigaciones penales. En efecto, si bien en estos casos el uso de prueba pericial por lo general ha permitido exonerar a las personas inocentes antes de haber sido condenadas, un problema detectado en muchos de ellos es la tardanza en su realización. Por ejemplo, al someter a análisis las evidencias físicas encontradas en los sitios del suceso o en el curso de la investigación.

Aparentemente, el problema de fondo estaría en la concepción que habría de las agencias de persecución penal sobre el rol de esta prueba. Así, se comprendería a la prueba pericial como una forma de asegurar una condena de una persona cuya culpabilidad ya creen establecida, lo que generaría pocos incentivos para su uso temprano ${ }^{63}$. De ahí, la recomendación básica que surge de esa literatura es que las pruebas periciales, particularmente los test de ADN, sean encargados tan pronto sea posible al inicio de la investigación, y de esta forma cumplan un rol diferente al que aparentemente les estarían dando las agencias de persecución penal ${ }^{64}$. En esta lógica, la prueba pericial se constituiría en una herramienta que permitiría desplegar una investigación y construir una teoría que explique los hechos del caso y no simplemente el rol de confirmar una versión que es la que los investigadores consideran ocurrió y de la cual están convencidos hace tiempo.

Como se puede observar en esta breve revisión de la evidencia disponible en el ámbito comparado, los problemas específicos que generan riesgos de condenas erróneas por mal uso de la prueba pericial se encuentran en niveles muy diversos de funcionamiento del sistema de justicia penal. Esto obliga a pensar en soluciones de orden sistémico más que enfrentarlas como resultado de circunstancias particulares de un perito o un caso específico.

\subsection{Dificultades en la valoración y confrontación de la prueba pericial producida en juicio}

Los problemas antes descritos se verían potenciados en el contexto de dos fenómenos relevantes, descritos por la literatura comparada, en relación a la producción y valoración en juicios orales de la prueba pericial: la tendencia de los jueces a otorgarle mayor peso a la prueba pericial que a otros medios y las dificultades de los litigantes de controlar en juicio la calidad de información que emana de los peritos. Explico brevemente cada uno.

${ }^{63}$ Gould et al. (2014 a). pp. 77-78.

${ }^{64}$ Gould et al. (2014 a). pp. p. 99, y Gould et al. (2014 b), pp. 511-512. 
Más allá de que en la mayoría de los países se cuenta con sistemas de libertad de valoración de la evidencia, existe una preocupación importante en la doctrina y jurisprudencia comparada, que tiene además algún respaldo empírico, acerca del riesgo de que jueces y jurados sobrevaloren a la prueba pericial ${ }^{65}$. Esta preocupación queda muy bien reflejada en la reflexión planteada por la Corte Suprema de los Estados Unidos en el caso Daubert, al señalar: "La prueba pericial puede ser tanto poderosa como bastante desorientadora debido a la dificultad para evaluarla"66. En nuestra tradición procesal también se han manifestado preocupaciones similares por parte de la doctrina. Así, por ejemplo, Taruffo ha dicho que "...como se dice tradicionalmente, el juez es peritus peritorum y, por lo tanto, debe ser capaz de valorar y controlar las bases y la opinión del perito. No obstante, ésta es sólo la teoría; en la práctica, el juez o el jurado no tienen a menudo el entrenamiento técnico o científico necesario para controlar de manera efectiva el trabajo del perito. Por ello la libre valoración de las pruebas periciales por parte del tribunal puede no ser nada más que una ficción, ya que el tribunal puede estar condicionado por una 'deferencia epistémica' hacia el experto $y$, entonces, puede ser que el perito determine realmente el contenido del veredicto judicial" ${ }^{\prime 67}$.

La preocupación consiste, entonces, que en la práctica los jueces le otorguen un peso más decisivo a la prueba pericial sobre el resto de la prueba. Eso se produciría, entre otros factores, por el aura especial que tiene las opiniones al provenir de expertos o por las dificultades que en ciertas materias se pueden producir para comprender adecuadamente los alcances de esta evidencia. Por lo mismo, el riesgo es que ella pueda influir indebidamente en decisiones de condenas más allá del valor real que debiera otorgársele. Así, por ejemplo, un estudio empírico reciente sobre el comportamiento de los jurados muestra que la credibilidad de un peritaje se construye tanto considerando el contenido de la pericia como en las características del experto. Además, que en la ponderación de ambas cuestiones existe mucho margen para considerar elementos que no son los más confiables y relevantes, lo que abre riesgos importantes de llegar a decisiones equivocadas basadas en una incorrecta valoración de esta prueba ${ }^{68}$. Por otra parte, existe también evidencia que muestra que los jueces profesionales

\footnotetext{
65 El riesgo de sobre evaluación de la prueba pericial sería una de las bases que explicaría, según algunos, el tratamiento especial que tiene la admisibilidad de esta prueba en países como los Estados Unidos. Schauer y Spellman (2013), pp. 3-4.

66 Citado en: Garret y Naufeld (2009), p. 9. (Traducción del autor).

67 TARUFFo (2008), pp. 96-97.

68 FreCKelton et al. (2016), pp. 202-203.
} 
no presentan diferencias significativas de comprensión de la evidencia que los jurados y, por lo mismo, que lo hacen tan bien o mal como ellos ${ }^{69}$.

Alguna literatura, relativamente reciente, ha cuestionado la base empírica sobre la cual se ha construido el temor a que los jueces en la práctica sobrevaloren la prueba pericial, indicando que la evidencia disponible sería, al menos, ambigua $^{70}$. Con todo, evidencia posterior, proveniente en algunos casos de estudios no disponibles en la época del trabajo citado, han mostrado que éste es un riesgo que debe ser considerado con seriedad ${ }^{71}$.

Por otra parte, los mismos autores que ponen en duda el riesgo de sobrevaloración han cualificado los alcances de su opinión, sosteniendo que éste se reduce significativamente cuando en el juicio ha existido una posibilidad real de cuestionar a esta prueba, ya sea por medio del trabajo de los litigantes en el contraexamen o por la producción de otra prueba pericial ${ }^{72}$. De esta forma, el riesgo se minimizaría en contextos en donde el sistema permite un escrutinio estricto a esta prueba. Por el contrario, si ese control no existe o es débil, reconocen que el riesgo efectivamente existe.

Esto me lleva a mencionar un segundo fenómeno para completar el cuadro que intento describir. La evidencia disponible en el ámbito comparado indica que los abogados litigantes tienen baja capacidad para someter a un control intenso de la calidad del trabajo de los peritos y sus declaraciones por vía de la ejecución de contraexámenes ${ }^{73}$. Por ejemplo, el estudio de Garret y Naulfeld del año 2009 concluye que los defensores raramente cuestionan el testimonio inválido presentado por peritos en juicio y en muy pocas ocasiones realizan contraexámenes exitosos a esos expertos. También encuentran que los defensores presentas fallas al momento de hacerse cargo de esa prueba en los alegatos de apertura y, además, que sólo en un porcentaje menor (19 de 137 casos) presentan expertos que pudieran cuestionar a los de la fiscalía, lo que hace que en la práctica la presentación de prueba pericial sea de un lado solamente ${ }^{74}$. En el estudio de Garret del año 2011 se repiten hallazgos similares. Por ejemplo, en un $50 \%$ del total de casos en donde se prestó un testimonio inválido de

\footnotetext{
69 Saks y Spellman (2016), p. 217.

70 Schauer y Spellman (2013), pp. 13-18.

71 FreCKelton et al. (2016), pp. 27-28 y 191-192.

72 Schauer y Speldman (2013), p. 16.

73 Citando diversos estudios sobre la capacidad real de cuestionar prueba pericial por medio de contraexámenes, Edmond concluye: "Más que un vehículo o motor capaz de exponer las debilidades y descubrir la verdad, los efectos de los contraexámenes son inconsistentes y a menudo mundanos". EDMOND (2011), p. 184.

74 Garret y Naufeld (2009), pp. 89-90.
} 
parte del perito los defensores ni siquiera realizaron una pregunta en el área en donde hubo testimonio erróneo ${ }^{75}$. Esto lo lleva a concluir que no se puede depender exclusivamente del proceso adversarial como forma de impedir los errores generados por el uso de la prueba pericial ${ }^{76}$.

En Australia, una reciente investigación empírica sobre juicios orales llevados ante jurados concluye, respecto a las prácticas de los abogados en casos de presentación de evidencia de ADN, que: "El hecho que expertos de la fiscalía presentando perfiles de ADN sean raramente cuestionados con éxito por defensores hábiles en los contraexámenes sirve para reforzar la percepción que este tipo de expertizaje es inviolable" $e^{\prime 77}$.

Por otra parte, también existe bastante información que muestra los límites que tiene la presentación de peritajes de refutación como mecanismo de control de la prueba pericial de incriminación ${ }^{78}$.

La suma de ambos fenómenos descritos, mayor peso en la práctica de este tipo de prueba y menor capacidad de control de su calidad por parte de los abogados y actores del sistema legal, generan el riesgo de resolver erróneamente si se ha presentado prueba pericial poco confiable, si los peritos prestan testimonio inválido o si se comportan derechamente mal. Existiendo algún debate sobre esto, la evidencia disponible pareciera plantear que es un entorno que se produce en el funcionamiento real de los sistemas de justicia criminal.

\section{4. ¿Qué sabemos sobre el uso de la prueba pericial y los errores del sistema en nuestro país?}

La preocupación por el impacto del uso de la prueba pericial en producir condenas erradas ha estado presente en el debate de la doctrina nacional, incluso durante la vigencia del sistema inquisitivo. Así, por ejemplo, Rafael Fontecilla, señalaba en su tratado que "Un error pericial puede torcer los dictados del juez. Y es por eso que el magistrado debe obrar con la debida cautela antes de aceptar

\footnotetext{
75 Garret (2011), p. 113.

76 Garret (2011), p. 114. En una dirección similar el reporte de la Academia Nacional de Ciencias de los Estados Unidos ha concluido que debido a las serias falencias que presentan jueces y abogados para lidiar con la presentación y evaluación de evidencia forense, los controles del sistema legal no son suficientes para corregir todos los problemas. National ReSEARCH CounciL (2009). p. 53.

77 FreCKelton et al. (2016), p. 198. (Traducción del autor).

78 Estos límites tienen que ver con las dificultades que normalmente enfrentan las defensas para conseguir en ciertas áreas expertos de calidad dispuestos a dar testimonios que contradigan a otros expertos; con sesgos en los jueces al valorar a estos expertos; $y$, finalmente, con las dificultades que tiene cuestionar efectivamente evidencia experta de dudosa calidad cuando ella se inserta a una narrativa coherente y más compleja como la que suelen presentar los fiscales en juicio. EDmOND (2011), pp.184-186.
} 
sus dictámenes". Luego de relatar un caso ocurrido hace muchas décadas en el país concluía "...y así, en la historia judicial se registran numerosos casos en que la justicia se ha desviado debido sólo a la ayuda de un cuerpo de peritos indoctos" ${ }^{\prime \prime 9}$.

Más reciénteme, en el contexto de funcionamiento de nuestro actual sistema acusatorio, Paillás ha destacado la importancia de la prueba pericial científica en el esclarecimiento de la verdad ${ }^{80}$. Por su parte, Castillo ha llamado la atención sobre los riesgos del uso de la prueba pericial en nuestro país para la condena de inocentes. Especialmente, ha destacado la existencia de problemas derivados de la enorme libertad que existe para presentar peritajes en el país, el poco control realizado por los intervinientes y jueces a los mismos, y la posición institucional en la que se desempeñan una gran parte de los peritos (en instituciones que son auxiliares del Ministerio Público o las propias policías) que los pone en una situación problemática desde el punto de vista de su imparcialidad ${ }^{81}$. En una dirección similar se han pronunciado otros trabajos ${ }^{82}$.

No obstante estos ejemplos, que dan cuenta de una preocupación que se ha mantenido en el tiempo, la revisión de la literatura nacional muestra que se trata de un tema que no ha sido objeto de investigación de corte empírico ni tampoco que hayan sido abordado de una manera sistemática los potenciales problemas. Ello obliga recurrir a diversas fuentes para construir una imagen preliminar y parcial de lo que estaría ocurriendo en la materia. A continuación revisaré dos fuentes de información disponibles que permiten construir una primera aproximación al tema en la práctica de nuestro país. La primera está constituida por la identificación de lo que se podría denominar como evidencia anecdótica, es decir, en la identificación de casos en los que el sistema ha cometido un error y ello se explica, al menos en parte, por el uso de la prueba pericial. La segunda fuente está constituida por las investigaciones académicas y periodísticas que se han producido en el tema y que permiten tener una imagen del comportamiento del sistema.

\subsection{Análisis de casos paradigmáticos de error}

Para efectos de este primer análisis me he valido de dos bases de datos que reúnen casos paradigmáticos de condenas erróneas o de errores graves del sistema. Por una parte, los casos registrados en la página web del Proyecto Inocentes

\footnotetext{
${ }^{79}$ Véase: FonteCilla, Rafael (1978), p. 286.

80 PaILLÁs, p. 112.

${ }^{81}$ Castillo (2013), pp. 290-293.

82 Por ejemplo, véase: DucE (2013 b), pp.101-105.
} 
de la Defensoría Penal Pública hasta el mes de marzo de 2016 y, por la otra, los casos contenidos en la base de datos de recursos de revisión decididos por la Corte Suprema en el período 2007-2015.

Parto por los casos identificados por el Proyecto Inocentes, una iniciativa creada por la Defensoría Penal Pública en el año 2013. Según lo que señala su página web, el proyecto pretende sensibilizar a la sociedad acerca de la posibilidad que el sistema de justicia penal cometa errores por medio de la identificación y documentación de casos en que ello ha ocurrido ${ }^{83}$. Para el cumplimiento de este objetivo, el proyecto selecciona casos paradigmáticos de personas que han sufrido las consecuencias de una persecución penal en la que han existido errores de diversa índole, que si hubieran sido detectados en forma oportuna habrían evitado la extensión de procesos y de resultados dañinos para estos individuos ${ }^{84}$.

Al mes de noviembre de 2016 el proyecto registraba 52 casos $^{85}$. Estos, en su gran mayoría no concluyeron con una condena, lo que podría arrojar dudas acerca de su uso como fuente para el tema de medir impacto de los reconocimientos en la condena de inocentes ${ }^{86}$. No obstante lo anterior, la literatura comparada en la materia ha venido señalado el interés de ampliar el análisis que tradicionalmente se ha realizado para cubrir, no sólo a los casos de personas condenadas, sino también aquellos que dan cuenta de errores del sistema entendidos de una manera más amplia. En este sentido, siguiendo a Forst, si bien muchos de estos casos de errores del sistema no corresponden exactamente al mismo problema que los de las condenas de inocentes, tratándose de las personas que han sufrido privaciones de libertad sin sentencia, las causas que los generan son similares y sus efectos igualmente devastadores ${ }^{87}$. Por lo mismo, aun tratándose de una fuente algo distinta, ella parece arrojar información de utilidad en la construcción de una visión empírica, al menos preliminar, sobre este problema en Chile.

${ }^{83}$ Disponible en: http://www.proyectoinocentes.cl/ [Visitado el 21 de diciembre de 2016].

${ }^{84}$ Para estos efectos el proyecto trabaja con un comité editorial integrado por funcionarios de la Defensoría Penal Pública y expertos externos quienes seleccionan los casos siguiendo un conjunto de criterios desarrollados. Mayor información puede verse en:

http://www.proyectoinocentes.cl/pag/33/365/comite_editorial [Visitado el 21 de diciembre de 2016].

${ }^{85}$ El listado completo de los casos puede verse en http://www.proyectoinocentes.cl/casos/listado/page/1 [Visitado el 21 de diciembre de 2016].

${ }^{86}$ En efecto, sólo uno de los casos del proyecto fue exonerado por un recurso de revisión. El resto concluyó por absolución, sobreseimiento definitivo y por uso de la facultad de no perseverar. Se trata del caso de Julio Robles que puede verse en http://www.proyectoinocentes.cl/casos/detalle/40/juliorobles_vergara [Visitado el 21 de diciembre de 2016].

87 FORST (2013), p.17. 
Una limitación adicional de esta base de datos es que el Proyecto Inocentes identifica sólo lo que considera como la principal causa de error en los casos seleccionados. Esto presenta límite para tener una visión más completa de la dinámica que los generó ya que -de acuerdo a la investigación disponible en el ámbito comparado- los casos de este tipo se caracterizan por una sucesión de eventos en la que confluyen diversos factores que comparecen al mismo tiempo, y que en su conjunto terminan explicando los errores del sistema o la condena de inocentes ${ }^{88}$. Aun con esta limitación, el análisis de estos casos entrega información útil no disponible en otras fuentes.

Del total de 52 casos, el proyecto identificó como causa principal el "error pericial o ciencia limitada" en cuatro de ellos. En lo que sigue describo muy someramente cada uno, poniendo énfasis en la descripción del problema central asociado con el uso de prueba pericial.

El primer caso es el de don Fernando Vásquez Mamani, quien el año 2003 fue sobreseído definitivamente por el delito de tráfico de estupefacientes, luego de haber estado 60 días en prisión preventiva producto de un examen preliminar realizado por la policía a un polvo de talco para los pies que había comprado y que arrojó que se trataba de droga (pasta base de cocaína). Vásquez sólo obtuvo su liberación luego de que, además de sostener su inocencia, las muestras se enviaran al Instituto de Salud Pública en Santiago (ISP) donde se practicó un examen que efectivamente acreditó de que se trataba de polvo para los pies ${ }^{89}$. En consecuencia, un examen inicial fallido generó una privación de libertad extendida que no tenía ninguna justificación.

Un segundo caso registrado en el Proyecto Inocentes es el de Alonso Etcheverría Martínez, quien en el año 2007 fue absuelto por un Tribunal Oral en lo Penal luego de haber estado 123 días en prisión preventiva, imputado como autor del delito de abuso sexual en contra de un niño. La persecución penal se sustentó en buena medida en la confección de un peritaje psicológico de credibilidad del relato que sostenía que la víctima era altamente creíble. Múltiple evidencia presentada en juicio descreditó tal versión y el tribunal consideró que el peritaje era especialmente poco fiable al ser elaborado con escaso

\footnotetext{
88 SimOn (2012), p. 7; Gould et al. (2014 b), pp.478- 483.

89 Mayores detalles del caso pueden verse en la página del Proyecto Inocentes: http://www.proyectoinocentes.cl/casos/detalle/10/fernando_vasquez-mamani [Visitado el 21 de diciembre de 2016]. Cabe señalar que al momento de practicar su detención se realizó un primer examen de campo que arrojó resultado negativo. Una vez detenido se efectuó uno nuevo que dio positivo y que permitió formalizar y obtener la prisión preventiva de Vásquez Mamani.
} 
rigor metodológico y ser "altamente incompleto y ambiguo" 90 . Nuevamente, entonces, una prueba pericial de poca confiabilidad sustenta la persecución penal y permite que la persona pase un período relativamente extenso privada de libertad mientras se desarrolla el proceso.

El caso de C.P.P.F. también corresponde al de un imputado absuelto en juicio oral el año 2013, luego de haber estado 220 días en prisión preventiva como presunto autor del delito violación en contra de la hija de su pareja de ocho años. Un elemento central que desencadenó la persecución penal fue el examen inicial realizado por un médico general no especialista que señaló encontrar signos de que se habría producido el delito. Esta prueba fue contradicha por peritajes realizados dos días después por especialistas y por el resto de la evidencia, todo lo que llevó al tribunal penal en lo oral a absolver poniendo especial énfasis en el mal procedimiento seguido en el peritaje inicial y que desencadenó el resto del proceso ${ }^{91}$.

Finalmente, el último caso en que el Proyecto Inocentes identifica como principal causa del error el uso de prueba pericial, es el de Elías Cartes Parra. Este individuo fue absuelto por un tribunal oral en lo penal el año 2014, luego de haber pasado 160 días en prisión preventiva y 90 días en arresto domiciliario, imputado por el delito de homicidio. Una prueba clave para inculparlo fue un peritaje químico realizado sobre una muestra de sangre encontrada en el baño del domicilio en donde se produjo el homicidio y que indicaba que correspondía al perfil genético de Cartes. Un examen pericial posterior encargado por su defensa pudo determinar que el peritaje original había sido realizado sin cumplir con un estándar científico básico exigido por la legislación nacional en la materia y ello no se había informado correctamente ${ }^{92}$. El tribunal oral absolvió considerando especialmente la falta de rigor científico de la prueba pericial en su contra ${ }^{93}$.

\footnotetext{
90 Mayores detalles del caso pueden verse en la página del Proyecto Inocentes: http://www.proyectoinocentes.cl/casos/detalle/8/alonso-etcheverria_martinez [Visitado el 21 de diciembre de 2016].

91 Mayores detalles del caso pueden verse en la página del Proyecto Inocentes: http://www.proyectoinocentes.cl/casos/detalle/26/c-p_p-f [Visitado el 21 de diciembre de 2016].

${ }_{92}$ Un extenso reportaje sobre el caso publicado por The Clinic en enero de 2014 el abogado defensor del caso describe así el problema "... La perito Shirley Villouta nos confirmó que la sangre no era de Elías. De un total de trece marcadores, alrededor de tres, no correspondían. Nuestra legislación, en el artículo 22 y 24 del de la Ley $N^{\circ}$ 19.970, dice que si encuentra dos o más debe informar que existe exclusión de la prueba". PIZARRO (2014).

${ }^{93}$ Mayores detalles del caso pueden verse en la página del Proyecto Inocentes: http://www.proyectoinocentes.cl/casos/detalle/42/elias-cartes_parra [Visitado el 21 de diciembre de 2016]. También recomiendo la revisión de un video explicativo del caso en:
} 
El análisis de la base de datos de la Corte Suprema de los recursos de revisión acogidos en el contexto del funcionamiento del sistema procesal penal acusatorio en el período 2007-2015 arrojó como resultado que en ninguno de los casos (48 en total) la condena errónea se vinculó al uso de prueba pericial ${ }^{94}$. No obstante lo anterior, se identificó a un caso resuelto por el sistema inquisitivo el año 2011 que presentaré debido a la enorme incidencia que tuvo el uso de la prueba pericial en la condena errónea que luego fue revertida por vía de la revisión. Además, se trata de un caso producido en un contexto temporal cercano y resuelto en forma paralela al funcionamiento del sistema acusatorio.

Se trata del caso de don Rodrigo Saavedra, quien fue condenado el año 2007 a cumplir 15 años en privación de libertad como autor del delito de violación en contra de su hija que a la época de los hechos tenía nueve años ${ }^{95}$. Saavedra alcanzó a cumplir cuatro años en la cárcel antes de obtener su libertad, luego de que el recurso de revisión que presentó fuera acogido por la Corte Suprema. Pruebas claves en su condena fueron un peritaje médico legal que afirmaba que la menor presentaba "desgarros antiguos del himen, ya cicatrizados, o sea, está desflorada en fecha no reciente ${ }^{\prime \prime 96}$. A esto se sumaba un examen médico previo hecho por cuatro doctores del hospital Calvo Mackenna que sostenían que la niña además tenía una enfermedad de transmisión sexual (gonorrea). En el recurso de revisión la Corte Suprema consideró especialmente -junto con prueba psicológica y la declaración de la propia víctima que a esa fecha ya era mayor de edad-la opinión expresada en un nuevo peritaje ginecológico que indicaba no se advertían elementos de actividad sexual y que la supuesta enfermedad de transmisión sexual que se le había diagnosticado originalmente podía incluso transmitirse en el embarazo y el parto. La Corte finalmente considera, sobre la base de diversa prueba acompañada con el recurso de revisión, que lo que se detectó fue una infección vaginal que la supuesta víctima había tenido desde los tres años según se había acreditado en el proceso y que a la época que le practicaron los exámenes originales aún persistía por inadecuado tratamiento.

\footnotetext{
http://www.proyectoinocentes.cl/sala_prensa/video_detalle/31/testimonio-de-elias-cartes-parra [Visitado el 21 de diciembre de 2016].

94 Este análisis se realizó gracias a la información entregada por la Unidad de Estudios de la Corte Suprema quienes me han facilitado planillas en Excel con la información de todos los casos de revisión presentados en el período en estudio. Los archivos electrónicos con esa información están en poder del autor.

95 Corte Suprema, rol No 2827-2011, de 28 de julio de 2011.

96 Junto con la sentencia de revisión, información detallada del caso puede revisarse en un extenso reportaje realizado por The Clinic sobre el mismo en octubre de 2013. Véase: Rojas (2013). También puede verse GonzÁlez SChmesSAne (2013).
} 
Además de las hipótesis de errores del sistema, la base de datos del Proyecto Inocentes permite identificar que también hay casos en donde se presenta el problema descrito en la sección previa como uso tardío de la prueba pericial ${ }^{97}$. El caso más paradigmático en esta dirección es el de Adrián Zarricueta Toro, quien fuera imputado por el delito de violación. No obstante presentarse voluntariamente a declarar y desde el primer momento sostener su inocencia (invocando como coartada que en la fecha del delito estuvo trabajando a cientos de kilómetros del lugar en donde éste ocurrió), Zarricueta alcanzó a estar 80 días en prisión preventiva antes que fuera liberado gracias a los resultados de una prueba de $A D N$ practicada sobre residuos biológicos que fueron encontrados en la víctima y que demostraron de manera concluyente que él no pudo ser el autor. El caso fue sobreseído definitivamente por la causal del artículo 250 letra b) del Código Procesal Penal (cuando apareciere claramente establecida la inocencia del imputado) el 21 de noviembre de 2013, casi cuatro meses después de que fue formalizado ( 31 de julio del mismo año ${ }^{98}$. Como se puede apreciar, si bien el caso concluye con una resolución favorable, resulta difícil comprender la demora en la obtención de resultados en una hipótesis en donde se estaba planteando la inocencia del imputado, él estaba privado de libertad y ya se disponía del material biológico que permitía practicar el examen ${ }^{99}$.

Quisiera agregar a los antecedentes expuestos en un caso no incluido dentro de la base de datos del Proyecto Inocentes, ni la de los recursos de revisión de la Corte Suprema, y que da cuenta de que el problema de mal comportamiento de los peritos también se ha dado en nuestro país. Se trata de un caso en el que se produjo una situación que podría ubicarse bajo la lógica de "fabricación" de prueba pericial descrita en el ámbito comparado y que revisé en forma previa. Me refiero al caso conocido como "Caso Larraín" del año 2013, que tuvo alta connotación pública al ser imputado del delito de conducción en estado de ebriedad con

\footnotetext{
${ }_{97}$ Un reportaje periodístico del año 2010 también da cuenta de un caso no incluido en el Proyecto Inocentes que podría caber en esta categoría. Véase, MIRANDA, Luis (2009): Salvados por el ADN, en: Revista Sábado. Disponible en: http://diario.elmercurio.com/detalle/index.asp?id=\{a5f11 cad-cf59-43ba9227-945004a69453\} [Visitado el 21 de diciembre de 2016].

${ }_{98}$ Mayores detalles del caso pueden verse en la página del Proyecto Inocentes: http://www.proyectoinocentes.cl/casos/detalle/46/adrian-zarricueta_toro [Visitado el 21 de diciembre de 2016]. También recomiendo la revisión de un video explicativo del caso, disponible en:

http://www.proyectoinocentes.cl/sala_prensa/video_detalle/33/testimonio-de-adrian-zarricueta [Visitado el 21 de diciembre de 2016].

${ }^{99}$ Esto puede contrastarse con lo ocurrido en el caso de Cristián López, también registrado el Proyecto Inocentes como un caso en donde el problema fue la realización de reconocimientos oculares de mala calidad, en el que en cambio la prueba de ADN demoró cinco días tras los cuales pudo obtener su libertad. Mayores datos pueden verse en http://www.proyectoinocentes.cl/casos/detalle/35/cristian lopez-rocha [Visitado el 21 de diciembre de 2016].
} 
resultado de muerte el hijo de un Senador de la República. En este se descubrió, producto de un segundo peritaje realizado sobre el cadáver de la víctima, que el informe de autopsia original practicado por un especialista del Servicio Médico Legal (en adelante SML) incorporó información falsa sobre procedimientos que nunca se realizaron en el cuerpo de la víctima ya que sus cavidades o el cráneo no fueron abiertos, cuestión que era observable a simple vista ${ }^{100}$. El perito terminó siendo condenado por estos hechos como autor del delito de falsificación de un instrumento público en enero de 2016 en un procedimiento abreviado ${ }^{101}$.

Como se puede apreciar a partir de la información recopilada, el uso de la prueba pericial en Chile efectivamente podría constituir un factor relevante en incrementar la probabilidad de un error del sistema de justicia penal. Los casos muestran que en nuestro país se repetirían algunos de los problemas específicos descritos en la literatura comparada que ya he descrito. Por ejemplo, el poco rigor metodológico en la realización de algunos peritajes, el apartamiento de los estándares disciplinares en la construcción de los informes, la falta de especialización de los supuestos expertos que los practican, su tardanza en la realización, entre otros. Si bien se trata de evidencia que podría ser considerada como anecdótica, ella muestra defectos muy profundos que no parece lógico pensar sólo se producen en casos específicos, por lo que la cifra negra podría ser importante. Por ejemplo, pensemos en el problema de falta de especialización de quienes los practican. Además, me parece construyen un caso plausible que nos obliga a mirar con más cuidado la forma en que esta prueba se está ejecutando y luego utilizando por nuestro sistema de justicia criminal. En definitiva, se trata de identificar una línea de futura investigación empírica importante.

\subsection{La investigación disponible sobre el uso de prueba pericial y su impacto en los errores del sistema}

Como ya he señalado, más allá de una preocupación general manifestada por diversos autores sobre la materia, esto no se ha traducido en investigaciones que de manera sistemática puedan arrojarnos un cuadro completo y actualizado acerca del uso de la prueba pericial en nuestro país. No obstante esto, algunos trabajos sobre áreas específicas de funcionamiento del sistema han mostrado

\footnotetext{
${ }^{100}$ Cuando el caso se destapó en la opinión pública, el perito reconoció a distintos medios de comunicación haber cometido errores en la elaboración de su peritaje, pero a su vez cumplido "como siempre" y redactado "bajo el modo habitual" su informe luego de tener más de 20 años de experiencia en la materia. Véase: Forensik: Caso Larraín: Perito Cuestionado Admite Errores en la Autopsia, 29 de octubre de 2013, en http://www.forensik.cl/novedades-de-forensik/noticias/836-caso-Larraín.html [Visitado el 21 de diciembre de 2016].

101 BAEZA (2016).
} 
una imagen bastante problemática sobre la materia, al dar cuenta de cuestiones similares a las descritas en el ámbito comparado como problemas específicos y que también son consistentes con lo ocurrido en los casos descritos previamente.

Las investigaciones de evaluación del nuevo proceso penal realizadas en los primeros años de funcionamiento de la reforma arrojaron algunos datos interesantes acerca del uso de la prueba pericial. El primero de ellos, contenido en la evaluación del año 2001, mostraba que todos los peritajes presentados en los juicios orales y simplificados observados fueron por parte del Ministerio Público ${ }^{102}$. Una evaluación del año 2003 mostró, por su parte, que a esa fecha la Defensoría Penal Pública no gastaba el total de su presupuesto asignado para realizar peritajes y que del total de los realizados sólo una porción muy menor (el 14,1\%) era presentado a juicio. A ello se sumaba que un porcentaje importante de estos peritajes presentados a juicio no se referían a materias que representaran un cuestionamiento sustantivo del caso, sino más bien estaban orientados a debatir la determinación de la pena u otras cuestiones accesorias ${ }^{103}$. En su conjunto, estas evaluaciones mostraban un cuadro en el que el cuestionamiento de la prueba pericial presentada por el Ministerio Público, por vía de la presentación de otros por parte de la defensa, era más bien una práctica excepcional. Testimonios más recientes de un perito del área médico forense con vasta experiencia en el sistema tienden a ratificar que este cuadro se ha mantenido en el tiempo ${ }^{104}$.

Un estudio publicado el año 2005 y realizado con el propósito de evaluar el comportamiento del sistema acusatorio en el tratamiento de delitos sexuales durante los primeros años de su funcionamiento, constató que en los juicios realizados en este tipo de casos existían severos problemas con el uso de la prueba pericial. Así, se detectó que existía una escasa capacidad de las partes en la audiencia de juicio oral para cuestionar la calidad de la metodología utilizada en la confección de los peritajes, la calidad de los expertos que presentaban sus opiniones y, finalmente, la calidad en la certeza de sus conclusiones. Además, se constató que los jueces tenían deficiencias para analizar adecuadamente el contenido de los peritajes y resolver de conformidad a éstos ${ }^{105}$. Respecto del uso de un tipo concreto, los pe-

102 Baytelman, pp. 125, 143.

103 Baytelman y Duce (2003), pp. 134-137.

104 "... la frecuencia con que querellantes o defensores presentan prueba pericial propia que contribuya a dar cuenta de vacíos, errores metodológicos o errores interpretativos en las pericias del SML, es ínfima". González (2013). Disponible en:

http://www.forensik.cl/novedades-de-forensik/columna-de-opini\%C3\%B3n-forense-en-chile/itemlist/ user/63-dr-leonardo-gonz\%C3\%A1 lez-wilhelm.html [Visitado el 21 de diciembre de 2016].

105 Véase: CASAS y Mera (2004), pp. 140-165. 
ritajes de credibilidad, las autoras concluyen que "... tiende, además, a suprimir la obligación del Tribunal de fundamentar justamente ese aspecto de la prueba. En otras palabras, los jueces descansan en las conclusiones del peritaje para afirmar un hecho (la veracidad o falta de veracidad de la víctima) que debiera ser fruto del razonamiento judicial fundado en la acumulación de pruebas y su análisis lógico." ${ }^{106}$ Como se puede apreciar, problemas muy similares a los descritos en la experiencia comparada se seguían presentando.

Literatura más reciente da cuenta de diversos indicios que muestran que la calidad de las pericias que suelen ser admitidas a juicio es problemática ${ }^{107}$. Así, un área en donde existen algunos estudios que han planteado cuestionamientos a la rigurosidad de las pruebas periciales es en materia de peritajes psicológicos. Estos han adquirido enorme protagonismo en el sistema y se presentan con bastante frecuencia, especialmente tratándose de delitos sexuales. Así, un estudio publicado el año 2005 daba cuenta de problemas serios de falta de formación especializada de los "expertos" que realizan los peritajes psicológicos; falta de investigación en el área de la psicología forense en el país; falta de homogeneidad en los procedimientos de evaluación; no uso de instrumentos de confiables y, en cambio, el uso de otros instrumentos con poca validación; agregándose, también, defectos en la elaboración de informes ${ }^{108}$. Investigaciones posteriores han evidenciado avances en la materia, pero también han manifestado preocupación por la persistencia en el tiempo de varios de estos problemas ${ }^{109}$. Un experto en el área de la psicología forense también ha identificado como un error frecuente en peritajes psicológicos y psiquiátricos de imputabilidad la existencia vicios lógicos en las opiniones que se formulan ${ }^{110}$.

Otras investigaciones han dado cuenta de tendencias jurisprudenciales poco claras en materia de favorecer un control estricto de la prueba pericial en juicio permitiendo el ingreso de las denominadas "metapericias" o peritajes sobre un

\footnotetext{
106 CASAS Y Mera (2004), p. 150.

107 En una entrevista realizada a Jorge Bofill el año 2011 se le pregunta por las causas que generan condenas erróneas en nuestro país. Él identifica como una de las principales las debilidades técnicas de los organismos auxiliares que produce prueba pericial. Así, sostiene "Te condenan porque hay un informe de peritos mal hecho, o porque en la persecución penal de delitos sexuales se transforma en moda usar livianamente determinadas pericias". Véase: PAdilla (2011), p. 14.

108 Véase: Condemarín y Macurán (2005), pp. 70-74.

109 Véase MACURÁn (2011), pp. 113-128; y, QUIJADA (2011), pp. 457-499.

110 Pavez (2016). Disponible en:

http://www.elmercurio.com/legal/noticias/opinion/2016/06/13/vicios-logicos-que-se-aprecian-en-laspericias-en-el-contexto-forense.aspx [Visitado el 21 de diciembre de 2016].
} 
peritaje. En efecto, la Corte Suprema ha manifestado una posición contradictoria en la materia, acogiendo o denegando nulidades basadas en su rechazo ${ }^{111}$.

La percepción negativa respecto a la calidad de la prueba pericial que se usa en nuestros procesos penales no ha estado presente sólo en el ámbito puramente académico y forense. En efecto, ha sido objeto de análisis y crítica al sistema en diversos trabajos de investigación periodísticos publicados por medios de comunicación social en años recientes. Por ejemplo, en materia de investigación de delitos sexuales en contra de niños, CIPER Chile publicó un interesante reportaje en octubre de 2013. En este, se mostraban falencias importantes en los peritajes producidos por el SML y otras agencias, derivadas de problemas de falta de especialización de sus expertos en ciertas materias, sobrecarga de trabajo con impacto en la calidad de los resultados, falta de procesos de formación institucionales de los peritos, demoras enormes en la producción de peritajes, entre otros ${ }^{112}$.

En otro reportaje más reciente (julio 2016) focalizado en el delito de violación, se describe como en los servicios de salud pública se recibe habitualmente a víctimas de estos delitos por médicos sin ninguna capacitación sobre elaboración de peritajes sexológicos. Se puede comprender sin mucha necesidad de explicación el impacto que esto puede tener en casos, como por ejemplo, el de C.P.P.F. que ya presenté. Según el reportaje, sólo el año 2014 se habría realizado una primera capacitación en estas materias organizada por el Ministerio de Salud en la cual se graduaron 48 médicos (34 del Servicio de Salud y 14 del SML) ${ }^{113}$.

Saliendo del ámbito de los delitos sexuales, la revista Qué Pasa publicó un reportaje el año 2014 mostrando también severos problemas en el funcionamiento del SML en materias como la mantención de la cadena de custodia de las evidencias, la rapidez excesiva y realización incompleta de exámenes periciales a víctimas, la falta de especialización de expertos, la sobrecarga de trabajo y falta de personal, entre otros ${ }^{114}$. Críticas similares a estas se repiten en otras investigaciones, aun cuando ellas no se focalizan en el proceso penal de manera exclusiva ${ }^{115}$. Por

111 DUCE (2013 b), pp. 104-105.

112 Villarrubia y Figueroa (2010). Disponible en: http://ciperchile.cl/2013/10/28/la-dolorosa-ruta-judicialque-recorren-los-ninos-abusados-sexualmente/ [Visitado el 21 de diciembre de 2016].Tomando esta crítica y ampliándola a un problema más general del SML puede verse la opinión de un médico forense en: GonZÁlez (2013). Disponible en:

http://www.forensik.cl/novedades-de-forensik/columna-de-opini\%C3\%B3n-forense-en-chile/itemlist/ user/63-dr-leonardo-gonz\%C3\%A1 lez-wilhelm.html [Visitado el 21 de diciembre de 2016].

113 DomeYko (2016), p. 40.

114 Maldonado (2014), pp. 42-46.

115 Un trabajo que muestra el desarrollo que poco a poco se ha ido dando en materia desarrollo de analistas criminalísticos privados como forma de lidiar con investigaciones policiales incompletas (incluyendo dentro de ella peritajes) puede ver en: Farías (2016), pp. 56-61. 
ejemplo, a propósito de un análisis de funcionamiento de la prueba pericial en los Tribunales de Familia, un reportaje de CIPER Chile de agosto de 2016 muestra cómo la demanda generada por esta jurisdicción ha producido una sobrecarga laboral en el SML y los proyectos de Diagnóstico Ambulatorio (DAM) que les impide atender la demanda adecuadamente ${ }^{116}$.

Como se podrá observar, investigaciones de diverso tipo tienden a consolidar algunos hallazgos, aun cuando se trata de trabajos parciales. En general ellos indican que hay prácticas específicas que aparentemente se darían en nuestro sistema, consistentes con aquellas que han sido identificadas en el ámbito comparado, y que tienen impacto en que la prueba pericial aumente la probabilidad de decisiones erróneas.

\section{A modo de conclusión}

Todos los sistemas de justicia criminal están expuestos a cometer errores graves al momento de decidir los casos que conocen. Es ingenuo pensar que, al menos en un porcentaje bajo, ellos no se van a producir. En este contexto, la investigación sobre los factores que producen estos errores no tiene por objetivo eliminarlos, sino más bien conocer mejor las dinámicas concretas de funcionamiento del sistema que llevan a su producción de manera de estar en condiciones de evitar las cuestiones más gruesas que los causan, de diseñar y adoptar medidas idóneas para prevenirlos, y en general de hacer todo lo posible por reducirlos al máximo.

La evidencia comparada muestra de manera consistente que el uso incorrecto de la prueba pericial es un factor que aumenta la probabilidad de cometer errores graves en un sistema de justicia penal, como por ejemplo, el condenar a personas inocentes. Ella permite también identificar algunos problemas específicos asociados a su uso que explicarían este fenómeno. Todo indica que se trata de aspectos de funcionamiento del sistema que podrían ser corregidos con la adopción de políticas en niveles tan diversos como capacitación de actores del sistema, la elaboración de reformas legales o la promoción de una mejora del nivel de especialización de los expertos que trabajan en las diversas materias, entre otros.

\footnotetext{
116 Por ejemplo: JaRA y AlBeRT (2016). Disponible en: http://ciperchile.cl/2016/08/30/tribunales-defamilia-las-graves-deficiencias-del-sistema-de-peritos/ [Visitado el 21 de diciembre de 2016]. En el mismo reportaje se recogen varias opiniones de actores y especialistas en Tribunales de Familia en los que se destaca el enorme peso que los jueces entregan usualmente a la prueba pericial que se presenta a pesar de la poca calidad de la misma y la escasa capacidad de los abogados litigantes para cuestionar esos informes periciales.
} 
La escasa información disponible en nuestro país da cuenta de que varios de los fenómenos descritos en el ámbito comparado efectivamente se estarían dando en el funcionamiento cotidiano del sistema. Si esto es así, estaríamos expuestos a riesgos similares a los documentados en el ámbito comparado. No obstante esto, se trata de un tema que no ha sido objeto de mayor preocupación en nuestro país. En ese contexto, este trabajo pretende constituir un primer paso en la dirección de generar mayor conciencia sobre el problema y su magnitud, dar a conocer la evidencia que se ha consolidado a nivel internacional, y ofrecer una primera mirada a la realidad nacional. Espero que también sirva para motivar el desarrollo de investigaciones empíricas y dogmáticas que complementen esta mirada. Por de pronto, esto es lo que pretendo hacer con la segunda parte de la investigación.

\section{Bibliografía CitadA}

Baytelman, Andrés (2001): Evaluación de la Reforma Procesal Penal Chilena (Santiago, Universidad Diego Portales y Universidad de Chile).

Baytelman, Andrés y Duce, Mauricio (2003): Evaluación de la Reforma Procesal

Penal: Estado de una Reforma en Marcha (Santiago, Universidad Diego Portales).

BBC (2015): "FBI Admits Forensic Evidence Errors in Hundreds of Cases", en: BBC news. Disponible en: http://www.bbc.com/news/world-us-canada-32380051 [visitado el 21 de diciembre de 2016].

Beecher-Monas, Erica (2007): Evaluating Scientific Evidence: An Interdisciplinary Framework for Intellectual Due Process (New York, Cambridge University Press).

Binder, Alberto (2013): "Prefacio", en: Duce, Mauricio, La Prueba Pericial (Buenos Aires, Editorial Didot), pp. 11-13.

BREYER, Stephen (2011): "Introduction", en: Federal Judicial Center, Reference Manual on Scientific Evidence, 3a edición (Washington, The National Academies Press), pp. 1-10.

Casas, Lidia y Mera, Alejandra (2004): Violencia de Género y Reforma Procesal Penal Chilena. Delitos Sexuales y Lesiones (Santiago, Facultad de Derecho Universidad Diego Portales).

Castillo, Ignacio (2013): "Enjuiciando al Proceso Penal Chileno desde el Inocentrismo (algunos apuntes sobre la necesidad de tomarse en serio a los inocentes)", en: Revista Política Criminal (Vol. 8, № 15), pp. 249-313.

Condemarín, Patricia y Macurán, Greter (2005): Peritajes Psicológicos sobre los Delitos Sexuales (Santiago, Editorial Jurídica de Chile). 
CutLer, Brian y Zapf, Patricia (2014): "Introduction: The Definition, Breadth, and Importance of Forensic Psychology", en: Cutler, Brian y Zapf, Patricia (eds.), APA Handbook of Forensic Psychology (Washington, American Psychological Association), volumen 1, pp. xvii-xxii.

Dennis, Ian (2010): The Law of evidence (Gran Bretaña, Sweet \& Maxwell).

Devis Echandía, Hernando (1984): Compendio de Pruebas Judiciales (Santa Fe, Rubinzal Culzoni Editores).

DomeYko, Antonia (2016): "La Denuncia: el Duro Camino de una Violación", en: Revista Ya ( $\left.N^{\circ} 1714\right)$, pp. 38-41.

Duce, Mauricio (2010): "Admisibilidad de la Prueba Pericial en Juicios Orales: un Modelo para Armar en la Jurisprudencia Nacional", en: Accatino, Daniela (coord.), Formación y Valoración de la Prueba en el Proceso Penal (Santiago, AbeledoPerrot), pp. 45-86.

Duce, Mauricio (2013 a): La Prueba Pericial (Buenos Aires, Ediciones Didot).

DucE, Mauricio (2013 b): "¿Debiéramos Preocuparnos de la Condena de Inocentes en Chile? Antecedentes Comparados y Locales para el Debate", en: Revista lus et Praxis (Año 19, № 1), pp. 77-138.

DWYeR, Déidre (2009): The Judicial Assessment of Expert Evidence (New York, Cambridge University Press).

EDMOND, Gary (2011): "Actual Innocents? Legal Limitations and Their Implications for Forensic Science and Medicine", en: Australian Journal of Forensic Sciences (Vol. 43, № 2-3), pp. 177-212.

EDmOnD, Gary (2013): "Introduction. Expert Evidence in Report and Courts", en: Australian Journal of Forensic Sciences (Vol. 45, № 3), pp. 248-262.

GonzÁlez SChmessane, Andrea (2013): "Hombre Falsamente Condenado por Violación Cuenta cómo Rehizo su Vida y Recuperó a su Hija", en: EMOL. Disponible en: http://www.emol.com/noticias/nacional/2013/09/26/621626/ colectivero-falsamente-condenado-por-violacion-le-dijo-al-ejecutivo-quevolvera-a-ver-a-ver-a-sus-ninas-finde.html [visitado el 21 de diciembre de 2016].

Farías, Roberto (2016): "El Auge de los Criminalistas Privados", en: Revista Paula ( No 1190), pp. 56-61.

FonteCilla, Rafael (1978): Tratado de Derecho Procesal Penal (Santiago, Editorial Jurídica), tomo II.

ForensIK (2013): "Caso Larraín: Perito Cuestionado Admite Errores en la Autopsia". Disponible en: http://www.forensik.cl/novedades-de-forensik/noticias/836caso-Larraín.html [visitado el 21 de diciembre de 2016]. 
FORST, Brian (2013): "Wrongful Convictions in a World of Miscarriages of Justice", en: Huff, Ronald y Killias, Martin (eds.), Wrongful Conviction and Miscarriages of Justice: Causes and Remedies in North American and European Criminal Justice Systems (New York, Routledge), pp. 15-43.

FPT Heads of Prosecutions Committee Working Group (2004): Report on the Prevention of Miscarriages of Justice (Canadá, Department of Justice).

FPT Heads of Prosecutions Committee (2011): The Path to Justice: Preventing Wrongful Convictions (Canadá FPT Heads of Prosecutions Committee).

Freckelton, Ian; Goodman-Delahunty, Jane; Horan, Jacqueline, y Mckimmie, Blake (2016): Expert Evidence and Criminal Jury Trials (Oxford, Oxford University Press).

Freckelton, Ian (2009): "Scientific Evidence", en: Freckelton, lan y Selby, Hugh, Expert Evidence, 4a Edición, (Victoria, Thomson Reuters), pp. 1120-1136.

Gascón, Marina (2013): "Prueba Científica. Un Mapa de Retos", en: Vásquez, Carmen (ed.), Estándares de Prueba y Prueba Científica (Madrid, Marcial Pons), pp. 181-202.

Garret, Brandon y Naufeld, Peter (2009): "Invalid Forensic Testimony and Wrongful Convictions", en: Virginia Law Review (Vol. 95, № 1), pp. 1-97.

Garret, Brandon L. (2011): Convicting the Innocent: Where Criminal Prosecutions Go Wrong (United States, Harvard University Press).

GILL, Peter (2014): Misleading DNA Evidence: Reasons for Miscarriages of Justice (Oxford, Academic Press), p. x.

GonZÁlezZ, Leonardo (2013): "El Lunes Negro del SML", en: Forensik. Disponible en: http://www.forensik.cl/novedades-de-forensik/columna-de-opini\%C3\%B3nforense-en-chile/itemlist/user/63-dr-leonardo-gonz\%C3\%A1lez-wilhelm. html [visitado el 21 de diciembre de 2016].

Gold, Alan (2003): Expert Evidence in Criminal Law: The Scientific Approach (Canadá, Irving Law).

Gould, Jon; Carrano, Julia; Leo, Richard y Young, Joseph (2013): Predicting Erroneous Convictions: A Social Science Approach to Miscarriages of Justice (Estados Unidos, National Institute of Justice).

Gould, Jon; Carrano, Julia; Leo, Richard; y Hall-Jares, Katie (2014 a): "Innocent Defendants: Divergent Cases Outcomes and What they Teach us", en: Zalman, Marvin y Carrano, Julia (edit.), Wrongful Conviction and Criminal Justice Reform (New York, Routledge), pp.73-89.

Gould, Jon; Carrano, Julia; LeO, Richard; y Hail-Jares, Katie (2014 b): "Predicting Erroneous Convictions", en: lowa Law Review (Vol. 99), pp. 471-522. 
HAACK, Susan (2003): "Inquiry and Advocacy, Fallibilism and Finality: Culture and Inference in Science and the Law", en: Law, Probability and Risk (Vol. 2), pp. 205-214.

HARRIS, David (2012): Failed Evidence: Why Law Enforcement Resists Science (New York, New York University Press).

Hirschberg, Max (1969): La Sentencia Errónea en el Proceso Penal (Trad. Tomás Banzhaf, Buenos Aires, Ediciones Jurídicas Europa-América).

House of Commons Science and Technology Committee (2005): Forensic Science on Trial (London, The Stationery Office Limited).

JACKSON, John D. y SUMmeRs, Sarah J. (2012): The Internationalisation of Criminal Evidence: Beyond the Common Law and Civil Law Traditions (Cambridge Cambridge University Press).

Jara, Matías y Albert, Carolina (2016): "Tribunales de Familia: las Graves Deficiencias del Sistema de Peritos", en: CIPER Chile. Disponible en: http:// ciperchile.cl/2016/08/30/tribunales-de-familia-las-graves-deficiencias-delsistema-de-peritos/ [visitado el 21 de diciembre de 2016].

JIAHON, He (2016): Back from the Dead: Criminal Justice and Wrongful Convictions in China (Honolulu, University of Hawai i Press).

Muñoz, Daniela y Zalazar Paulina (2014): "Chile es el País de A. Latina que Más Subió en Cobertura en Educación Superior en 10 años", en: La Tercera. Disponible en: http://diario.latercera.com/edicionimpresa/chile-es-el-paisde-a-latina-que-mas-subio-en-cobertura-en-educacion-superior-en-10-anos/ [visitado el 21 de diciembre de 2016].

Baeza, Angélica (2016): "Condenan a Médico que Falsificó Autopsia de Víctima de Martín Larraín", en: La Tercera. Disponible en: http://www.latercera. com/noticia/nacional/2016/01/680-664173-9-condenan-a-medico-quefalsifico-autopsia-de-victima-de-martin-Larraín.shtml [visitado el 21 de diciembre de 2016].

Macurán, Greter (2011): La Prueba Pericial Psicológica en los Delitos de Abuso Sexual Infantil (Santiago, Editorial Jurídica de Chile).

MAIER, Julio (2011): Derecho Procesal Penal (Buenos Aires, Editores del Puerto), tomo III.

Maldonado, Emilio (2014): "Autopsia al SML", en: Revista Qué Pasa (№ 2232), pp. 42-46.

Mauet, Thomas A. (2007): Estudios de Técnicas de Litigación (Traducc. Karen Ventura y Luis Miguel Reyna, Perú, Jurista Editores). 
Ministry of Justice (2013): The Government's Response to the Law Commission Report: Expert Evidence in Criminal Proceedings in England and Wales (Inglaterra, Ministry of Justice).

Miranda, Luis (2009): "Salvados por el ADN", en: Revista Sábado. Disponible en: http://diario.elmercurio.com/detalle/index.asp?id=\{a5f11 cad-cf59-43ba9227-945004a69453\} [visitado el 21 de diciembre de 2016].

Murphy, Erin (2015): Inside the Cell: The Dark Side of Forensic DNA (New York, Nation Books).

National Research Council (2009): Strengthening Forensic Science in the United States: A Path Forward (Washington, The National Academies Press).

Naughton, Michael (2013): The Innocent and the Criminal Justice System. A Sociological Analysis of Miscarriages of Justice (United Kingdom, Palgrave Macmillan).

Paillás, Enrique (2002): La Prueba en el Proceso Penal Oral (Santiago, Conosur Lexis-Nexis).

Padilla, Marcelo (2011): "Examen \& Contraexamen", en: Revista 93 ( $\left.N^{\circ} 6\right)$, pp.12-17.

Paenza, Adrián (2013): "Sally Clark", en: Página 12. Disponible en:

https://www.pagina12.com.ar/diario/contratapa/13-214264-2013-02-20.html [visitado el 21 de diciembre de 2016].

Pavez, Mauricio (2016): "Vicios Lógicos que se Aprecian en las Pericias en el Contexto Forense", en: El Mercurio Legal. Disponible en: http://www. elmercurio.com/legal/noticias/opinion/2016/06/13/vicios-logicos-que-seaprecian-en-las-pericias-en-el-contexto-forense.aspx [visitado el 21 de diciembre de 2016].

Peterson, Joseph; Sommers, Ira; Baskin, Deborah; y Johnson, Donald (2010): The Role and Impact of Forensic Evidence in the Criminal Justice Process (Washington, National Institute of Justice).

QuiJADA, Diego (2011): “Aportes al Debido Proceso Penal en Evaluación Pericial Psicológica y Psiquiátrica a Imputados en Delitos Sexuales: ¿Existe Relación de Coherencia entre Solicitud y Respuesta Pericial?", en: Fuentes, Claudio (Comp.), Diez Años de la Reforma Procesal Penal en Chile (Santiago, Ediciones Universidad Diego Portales), pp. 457-499.

ROACH, Kent (2009): "Forensic Science and Miscarriages of Justice: Some Lessons from a Comparative Perspective", en: Jurimetrics ( $N^{\circ} 50$ ), pp. 67-92. 
ROACH, Kent (2010): "Wrongful Convictions: Adversarial and Inquisitorial Themes", en: North Carolina Journal of International Law and Commercial Regulation (Vol. 35, № 2), pp. 387-446.

Roberts, Paul (2013): “¿Fue el Bebé Sacudido?, Prueba Pericial y Epistemología Jurídica en el Proceso Penal Inglés", en:Vásquez, Carmen (ed.), De la Prueba Científica a la Prueba Pericial. Ensayos de Epistemología Jurídica (Madrid, Marcial Pons), pp. 134-180.

Roxın, Claus (2003): Derecho Procesal Penal, 25a Edición (Traducc. Gabriela Córdoba y Daniel Pastor, Buenos Aires, Editores del Puerto).

Saks, Michael y Spellman, Barbara (2016): The Psychological Foundations of Evidence Law (New York, New York University Press).

SAlORT, Antonio (1949): La Evolución Histórica de la Prueba Pericial y Apreciación de su Valor o Fuerza Probatoria (Córdoba, Assandri).

Schauer, Frederick y Spellman, Barbara (2013): "Is Expert Evidence Really Different?", en: Notre Dame Law Review (Vol. 89), pp. 1-26.

SeRvick, Kelly (2016): "Reversing the Legacy of Junk Science in the Courtroom", en: Science Magazine. Disponible en: http://www.sciencemag.org/ news/2016/03/reversing-legacy-junk-science-courtroom [visitado el 21 de diciembre de 2016].

Stella, Federico (2003): Giustizia e Modernitá. La Proteezione dell'Inocente e la Tutele delle Vittime, 3a Edición (Milán, Giuffrè Editore).

SIMON, Dan (2012): In Doubt: The Psychology of the Criminal Justice Process (United States, Harvard University Press).

Taruffo, Michele (2008): La Prueba (Traducc. Laura Manríquez y Jordi Ferrer Beltrán, Madrid, Marcial Pons).

RojAs, Jorge (2013): "Los 1.302 días de Rodrigo Saavedra en la ex Penitenciaría", en: The Clinic. Disponible en:http://www.theclinic.cl/2013/10/14/los1-302-dias-de-rodrigo-saavedra-en-la-ex-penitenciaria/ [visitado el 21 de diciembre de 2016].

Pizarro, Claudio (2014): "El Crimen del Cura Fernández", en: The Clinic. Disponible en:

http://www.theclinic.cl/2014/01/30/el-crimen-del-cura-fernandez/ [visitado el 21 de diciembre de 2016].

RozenberG, Joshua (2014): "Are Juries Being Blinded by Science?", en: The Guardian. Disponible en: http://www.theguardian.com/law/2014/oct/15/ juries-blinded-science-lord-chief-justice-primers [visitado el 21 de diciembre de 2016]. 
The Law Commission (2009): "The Admissibility of Expert Evidence in Criminal Proceedings in England and Wales". Disponible en: http://www.lawcom.gov. uk/wp-content/uploads/2015/03/cp190_Expert_Evidence_Consultation.pdf [visitado el 21 de diciembre de 2016].

The Law Commission (2011): "Expert Evidence in Criminal Proceedings in England and Wales". Disponible en: https://www.gov.uk/government/uploads/system/ uploads/attachment_data/file/229043/0829.pdf [visitado el 21 de diciembre de 2016].

Hsu, Spencer (2012): "Convicted Defendants Left Uninformed of Forensic Flaws Found by Justice Dept.", en: The Washington Post. Disponible en: http://www. washingtonpost.com/local/crime/convicted-defendants-left-uninformed-offorensic-flaws-found-by-justice-dept/2012/04/16/gIQAWTcgMT_story.html [visitado el 21 de diciembre de 2016].

Thomas, Sabra (2015): "Addressing Wrongful Convictions: An Examination of Texas's New Junk Science Writ and other Measures for Protecting the Innocent", en: Houston Law Review (№ 52), pp. 1037- 1068.

VÁsquez, Carmen (2015): De la Prueba Científica a la Prueba Pericial (Madrid, Marcial Pons).

Villarrubia, Gustavo y Figueroa, Juan Pablo (2010): "La Dolorosa Ruta Judicial que Recorren los Niños Abusados Sexualmente", en: CIPER Chile. Disponible en: http://ciperchile.cl/2013/10/28/la-dolorosa-ruta-judicial-que-recorrenlos-ninos-abusados-sexualmente/ [visitado el 21 de diciembre de 2016]. 